DOE/NASA/0367-1

NASA CR-179514

AV-FR-86/822

\title{
Development and Testing of Vortex Generators for Small Horizontal Axis Wind Turbines
}

(NASA-CB-179514) CEVELCEMENT ANC TESTING OF VCRTEX GENERATOES FCR SHAIL HCEIZCNTAL AXIS HIND TUREINES Eiral Gefort (AETCVironment, InC-) $45 \mathrm{p}$

G.W. Gyatt

AeroVironment Inc.

July 1986

Prepared for

NATIONAL AERONAUTICS AND SPACE ADMINISTRATION

Lewis Research Center

Under Contract DEN 3-367

for

U.S. DEPARTMENT OF ENERGY

Conservation and Renewable Energy Wind/Ocean Technology Division 


\section{DISCLAIMER}

This report was prepared as an account of work sponsored by an agency of the United States Government. Neither the United States Government nor any agency thereof, nor any of their employees, makes any warranty, express or implied, or assumes any legal liability or responsibility for the accuracy, completeness, or usefulness of any information, apparatus, product, or process disclosed, or represents that its use would not infringe privately owned rights. Reference herein to any specific commercial product, process, or service by trade name, trademark, manufacturer, or otherwise, does not necessarily constitute or imply its endorsement, recommendation, or favoring by the United States Government or any agency thereof. The views and opinions of authors expressed herein do not necessarily state or reflect those of the United States Government or any agency thereof.

Printed in the United States of America

Available from

National Technical Information Service

U.S. Department of Commerce

5285 Port Royal Road

Springfield, VA 22161

NTIS price codes 1

Printed copy: $\mathrm{A03}$

Microfiche copy: A01

1Codes are used for pricing all publications. The code is determined by the number of pages in the publication. Information pertaining to the pricing codes can be found in the current issues of the following publications, which are generally available in most libraries: Energy Research Abstracts (ERA); Government Reports Announcements and Index (GRA and 1); Scientific and Technical Abstract Reports (STAR); and publication, NTIS-PR-360 available from NTIS at the above address. 
DOE/NASA/0367-1

NASA CR-179514

AV-FR-86/822

\section{Development and Testing of Vortex Generators for Small Horizontal Axis Wind Turbines}

G.W. Gyatt

AeroVironment Inc.

Monrovia, California 91016-3424

July 1986

Prepared for

National Aeronautics and Space Administration

Lewis Research Center

Cleveland, Ohio 44135

Under Contract DEN 3-367

for

U.S. DEPARTMENT OF ENERGY

Conservation and Renewable Energy

Wind/Ocean Technology Division

Washington, D.C. 20545

Under Interagency Agreement DE-Al01-76ET20320 


\section{TABLE OF CONTENTS}

$\begin{array}{lr}\text { INTRODUCTION } & 1 \\ \text { TIICIINICAI, DISCUSSION } & 0 \\ \text { IIIIIIT TISST } & 21 \\ \text { DISCUSSION OF RESULTS } & 25 \\ \text { CONCLUSIONS } & 36 \\ \text { RECOMMENDATIONS } & 38 \\ \text { REFERENCES } & 39 \\ \text { APPENDIX } & 40\end{array}$




\section{INTRODUCTION}

In the continuing quest for improved wind turbine performance, the addition of vortex generators to the rotor blades is potentially the simplest, and most cost-effective method for increasing the annual energy production in both planned and existing machines. A typical horizontal axis design calls for airfoils with both a high thickness-to-chord ratio for strength, a high lift-to-drag ratio for performance, and a large maximum lift coefficient in order to keep the solidity (and therefore the gale loads) low. High lift coefficients can be achieved either using thin, highly cambered airfoils, or with thick sections with small camber. The former is generally unsuitable for wind turbines because of strength requirements, while the latter typically has a higher drag. The designer is therefore faced with an undesirable trade-off between performance and strength. Further discussion on airfoil requirements for wind turbine applications can be found in Lissaman and Walker (1979).

In addition, several existing wind turbines suffer a considerable performance degradation due to an accumulation of bugs and dirt on the leading edge of the rotor blades. This roughness, which tends to produce premature boundary layer transition, results in a higher drag coefficient and can cause early stalling of the airfoil.

Both of these problem areas would benefit from some sort of boundary layer control to increase the resistance of the boundary layer to adverse pressure gradients; this would delay separalion and allow the airfoil to reach a higher maximum lift coefficient hopefully without a large drag penalty. There are basically two methods of achieving this. One is to suck the boundary layer away into the airfoil surface using surface slots or porous surface materials, the other is to re-energize the boundary layer fluid which has been slowed by viscous effects. Re-energization can be achieved either by mixing the boundary layer fluid with faster moving fluid from the free stream or by blowing high energy fluid directly into the boundary layer from a separate source using surface slots.

The aspiration techniques are relatively complicated to implement, involving considerable duct work and a power source (representing an equivalent drag coefficient) - not very practical as a 'fix' for an existing wind turbine - and are mentioned here only as background discussion. Enforced mixing of the free stream and boundary layer fluids is a more tractable solution to the wind turbine problem. This phenomenon occurs naturally in a turbulent boundary layer and one simple 'fix' used to extend the performance of a number of airfoils is to add a trip strip - a small step or band of roughness perpendicular to the flow direction - to the upper surface to force the transition of a previously laminar boundary layer to a turbulent one. However, the rate of momentum transfer in a turbulent boundary layer is limited by the magnitude of the turbulence; if the rate could be increased further, there would be the potential for greater performance improvements. 
Vortex generators provide a simple method of increasing this mixing rate. They were first proposed at the United Aircraft Corporation and are due largely to Taylor (1947) and Bruynes (1951). In their simplest form, they consist of small vanes projecting normal to the surface at an angle of attack to the incoming flow so that they behave like half wings and generate trailing vortices from their tips. They can be arranged parallel or with alternate vanes at positive and negative angles of incidence producing sets of corotating or counterrotating vortices respectively (figure 1 ). Other designs are possible (figure 2), all having the common aerodynamic feature that they shed a trailing vortex. They have been used to good effect in suppressing or delaying separation in diffusers, bends, wings (Taylor, 1947), and more recently, on the large Boeing MOD-2 wind turbine (Miller, 1984). It should be noted that vortex generators, by creating an energetic vortex, necessarily incur a drag penalty under flow conditions when separation is not imminent, but in a good design this effect is small compared with the performance gain under other operating conditions. Their effectiveness depends on their position relative to the point where separation is liable to occur and tend to function best where the adverse pressure gradients inducing separation are not severe (Tanner et al., 1954).

As an example of the magnitude of the performance increase that can be expected, McCullough et al. (1951) measured an increase in maximum lift coeflicient from 1.33 to 1.89 (42\%) when vortex generators were added to the $18 \%$ thick NACA $63_{3}-018$ airfoil with a drag penalty no greater than 0.002 on a base line drag on the order of 0.01 and a drag reduction above $\mathrm{C}_{\mathrm{L}}=1.1$. More recently, Sullivan (1984), using performance test results, has projected up to a $20 \%$ increase in annual energy production for the MOD- 2 wind turbine following the addition of vortex generators.

The maximum lift coefficient of an airfoil can also be increased by the addition of trailing edge or nose flaps, slats, variable camber, and other devices, but all of these involve mechanical complexity, and generally increase drag. The simplest technique for increasing the maximum lift coefficient of an airfoil is by the addition of roughness or properly located and sized vortex generators, the latter being much more effective in delaying separation than roughness induced turbulence. Although some airfoils will not respond to these methods, there exists a wide class of thick airfoils for which vortex generators represent a simple positive and passive add-on which will provide a significant improvement in maximum lift coefficient with only a very small increase in drag.

In general, it is found that the most effective design of vortex generators for the upper surface of an airfoil calls for a single row of flat fins perpendicular to the surface near the leading edge (at about $10 \%$ chord) with a height of one or two percent of the chord, a length of about two or three percent, and an angle of attack around $15^{\circ}$ to $20^{\circ}$, a spacing on the order of ten times their height, and 
corotational pattern
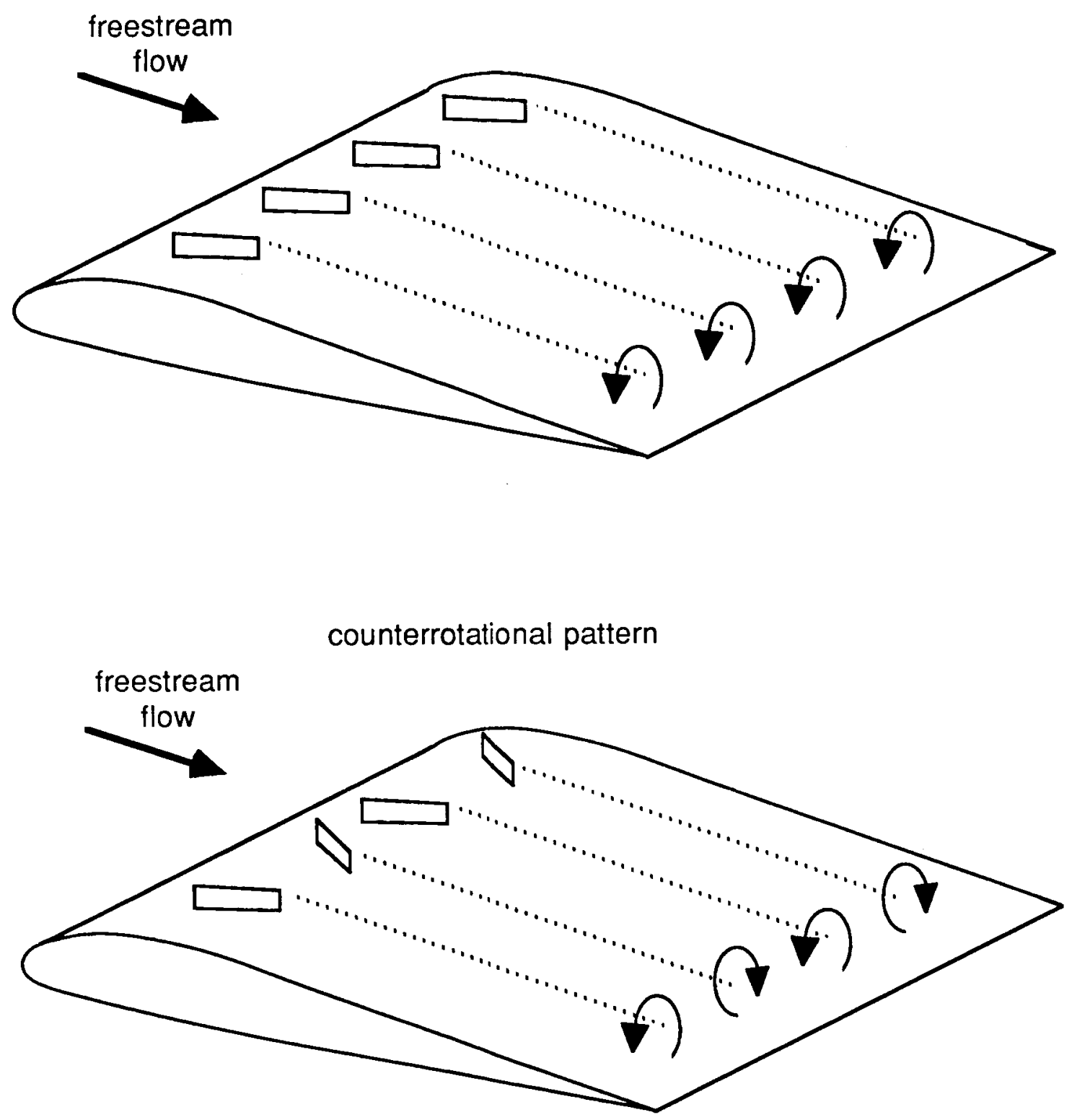

FIGURE 1. - COMPARISON OF COROTATIONAL AND COUNTERROTATIONAL PATTERNS OF VANE-TYPE VORTEX GENERATORS. 


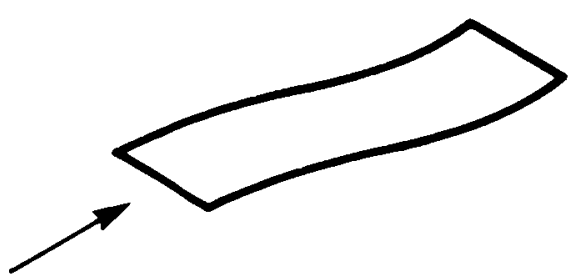

SIMPLE PLOW
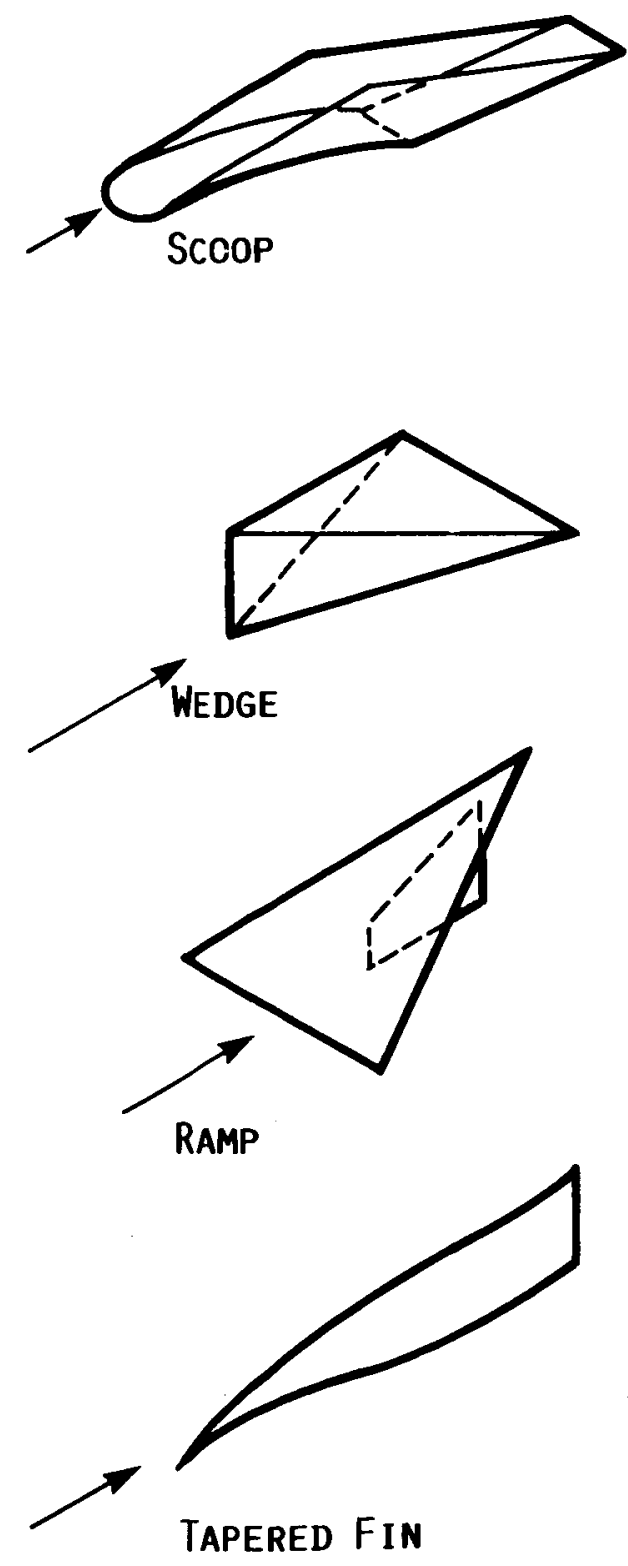

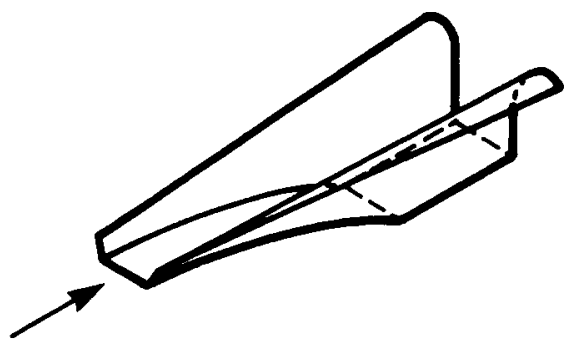

Shielded Plow
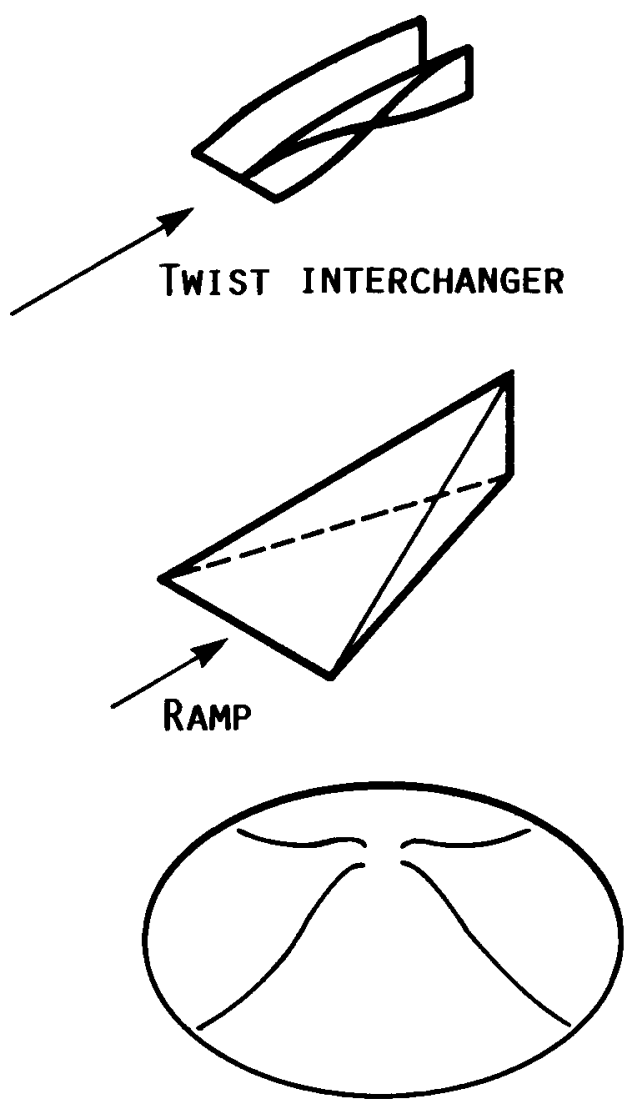

DOME

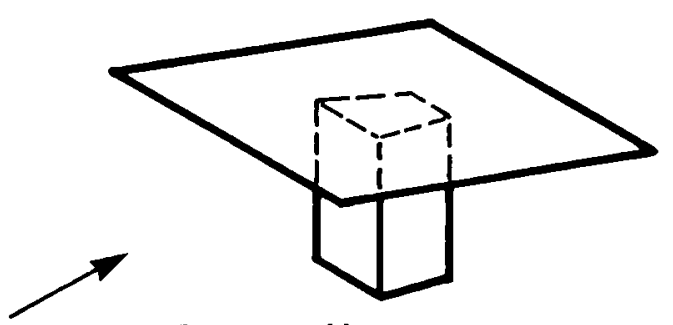

FINITE WING

FIGURE 2. - VARIOUS TYPES OF VORTEX GENERATORS AND BOUNDARY LAYER MIXING DEVICES. 
arranged in the counterrotating pattern. Jones (1957) has made a theoretical analysis of the paths of the shed vortices as they proceed downstream and this provides a tool for designing alternative arrangements.

Other vortex generator designs tend not to be as effective. Tanner et al. (1954) have made extensive tests on small lifting surfaces mounted roughly parallel to the surface and offset by a short distance (figure 2) - a useful design where low yaw sensitivity is required. McCullough, et al., 1951 experimented with so-called boundary layer wedges, while Stephens, et al., 1955 studied ramps (figure 2). These are usually triangular in planform mounted with the upstream end in contact with the surface and the other end raised slightly above it. They appear to be as effective as the vertical fin type in delaying separation, but at a somewhat greater cost in extra drag when separation is not imminent. Schubauer and Spangenberg (1959) compared a large number of different designs and reached similar conclusions.

In this study, a counterrotating flat fin design was used to modify the performance of a small horizontal axis wind turbine (HAWT), the Carter Model 25. Although this is one of the simplest vortex generator designs, it is generally effective and has produced substantial performance improvements during recent tests on the large MOD-2 (Miller, 1984; Sullivan, 1984) and medium size MOD-0 wind turbines (Corrigan and Savino, 1985; Savino, 1985). 


\section{TECHNICAL DISCUSSION}

Three basic sets of parameters can be identified in a definition of a particular arrangement of vortex generators. These are size, location and orientation. Length and height define size, spanwise spacing and chordwise position determine location, and orientation is defined by angle of incidence. The design values for the vortex generators used in these tests are discussed in detail below. The successful arrangement of vortex generators used on the MOD-2 were used as a starting point to reach a design for the much smaller Carter machine.

\section{- Vortex generator sizing considerations}

Three different sizes of vortex generators were used on the MOD-2 machine, the largest for the inboard third of the blade, the smallest for the outboard third, and an intermediate size for the mid-span section. Figure 3 records the locations of these three sections of the MOD-2 blade and the sizes of vortex generators used. Figure 4, reproduced from Sullivan, shows pictures comparing the sizes of the actual vortex generators and their scale relative to the blade.

Following this approach, the Carter blade was also divided into three sections as shown in figure 5. The mean properties of each section of the two blades are listed in tables 1 and 2 . It can be seen that the Reynolds numbers differ by about a factor of 10 .

Two basic approaches were considered for sizing the vortex generators for the Carter blades; the first and simplest was to make a simple geometric scaling, while the second and more sophisticated method was to scale according to the boundary layer thickness. The boundary layer thickness at the $10 \%$ mean chord point has therefore been estimated for both laminar and turbulent cases using formulae from studies of flat plates - a simple but reasonable first approximation for comparison purposes. It should be remembered that the purpose of vortex generators is primarily to delay the onset of stall, and they should therefore be designed for this condition. The thicknesses of both types of boundary layer have been estimated since we cannot be sure which best represents the actual conditions on the blade. As the start of the adverse pressure gradient moves closer to the leading edge, there is a tendency for the boundary layer to undergo transition earlier. While it is likely that, because of the low Reynolds number, the boundary layer on the Carter blade is laminar up to at least the $10 \%$ chord position even near stall, the same cannot necessarily be said of the MOD-2 blade with Reynolds numbers on the order of $10^{6}$. It can be seen that while the laminar thicknesses differ by a factor of about 2 , the turbulent thicknesses differ by about 4 .

Table 3 compares the ratios of vortex generator height to boundary layer thickness and vortex generator length to blade chord for the MOD-2 designs. It is noted that the vortex generator "aspect ratio", defined as the height to length ratio, was $1 / 4$ in each case. It is seen that to a close 


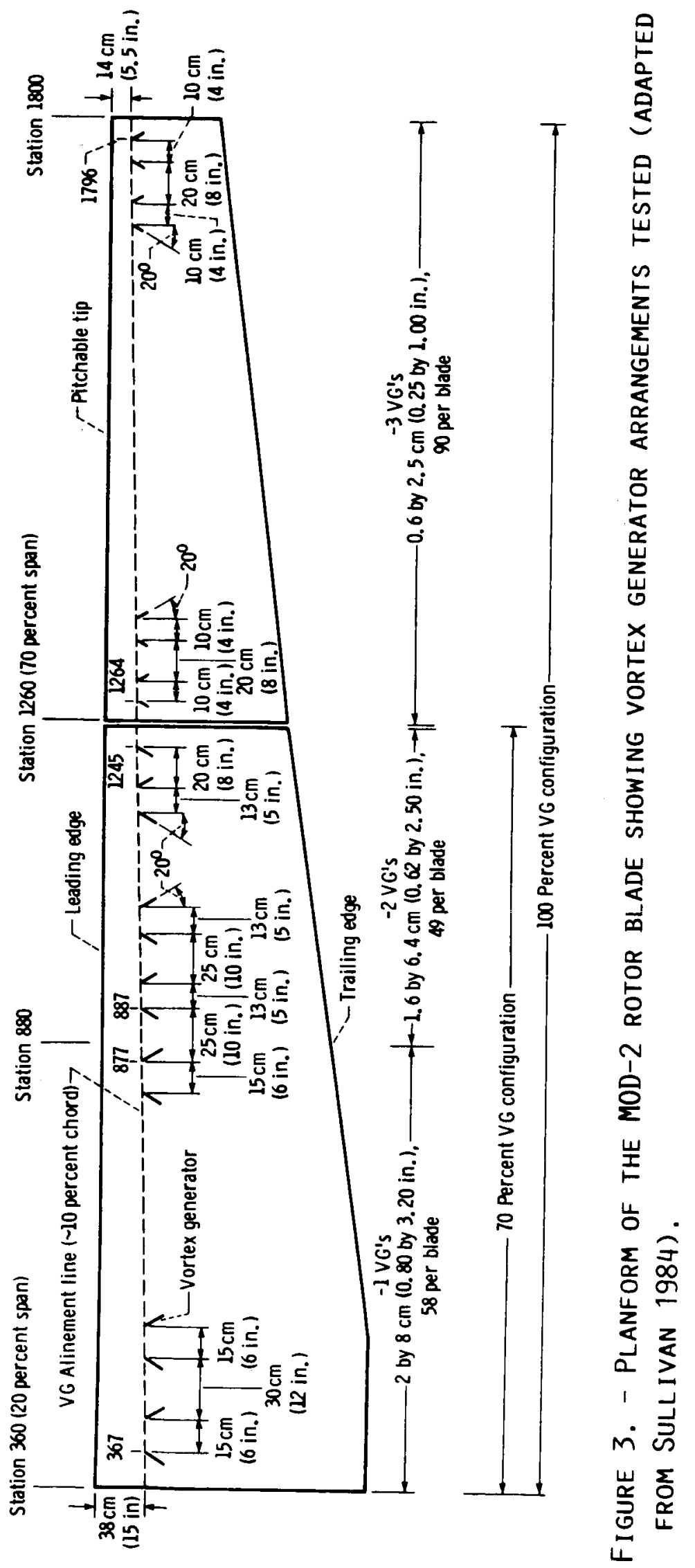



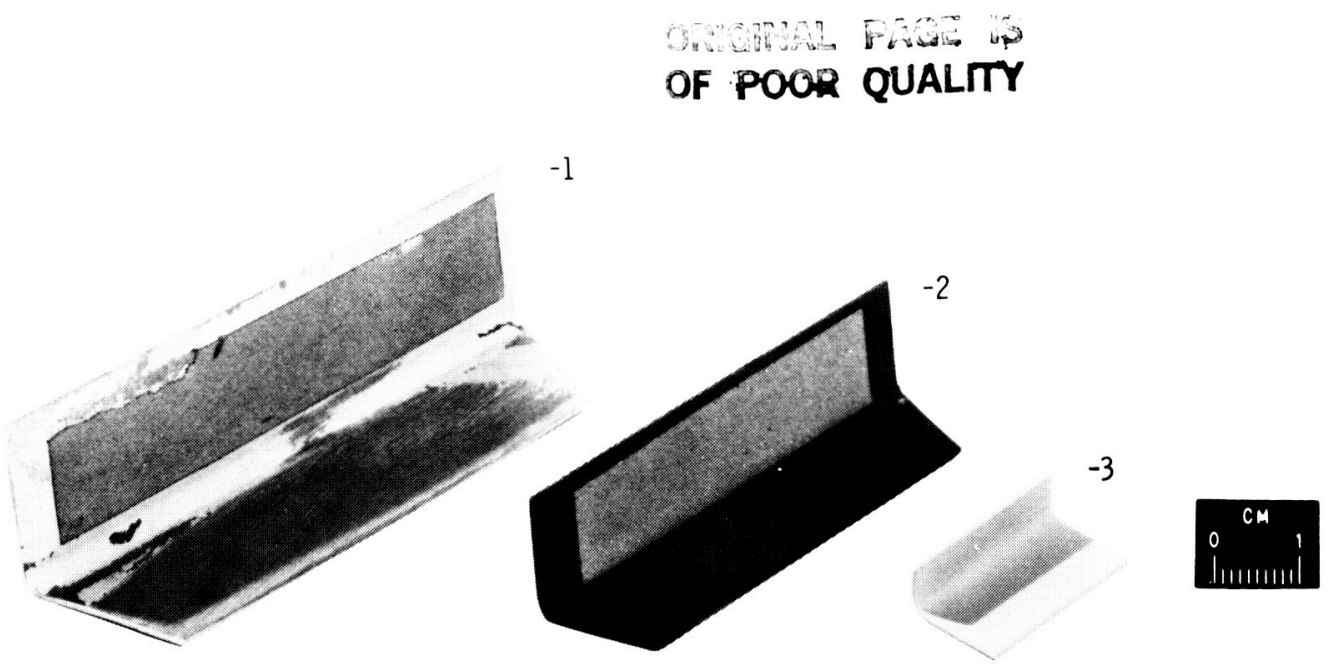

(A) THREE SIZES OF VORTEX GENERATORS TESTED.

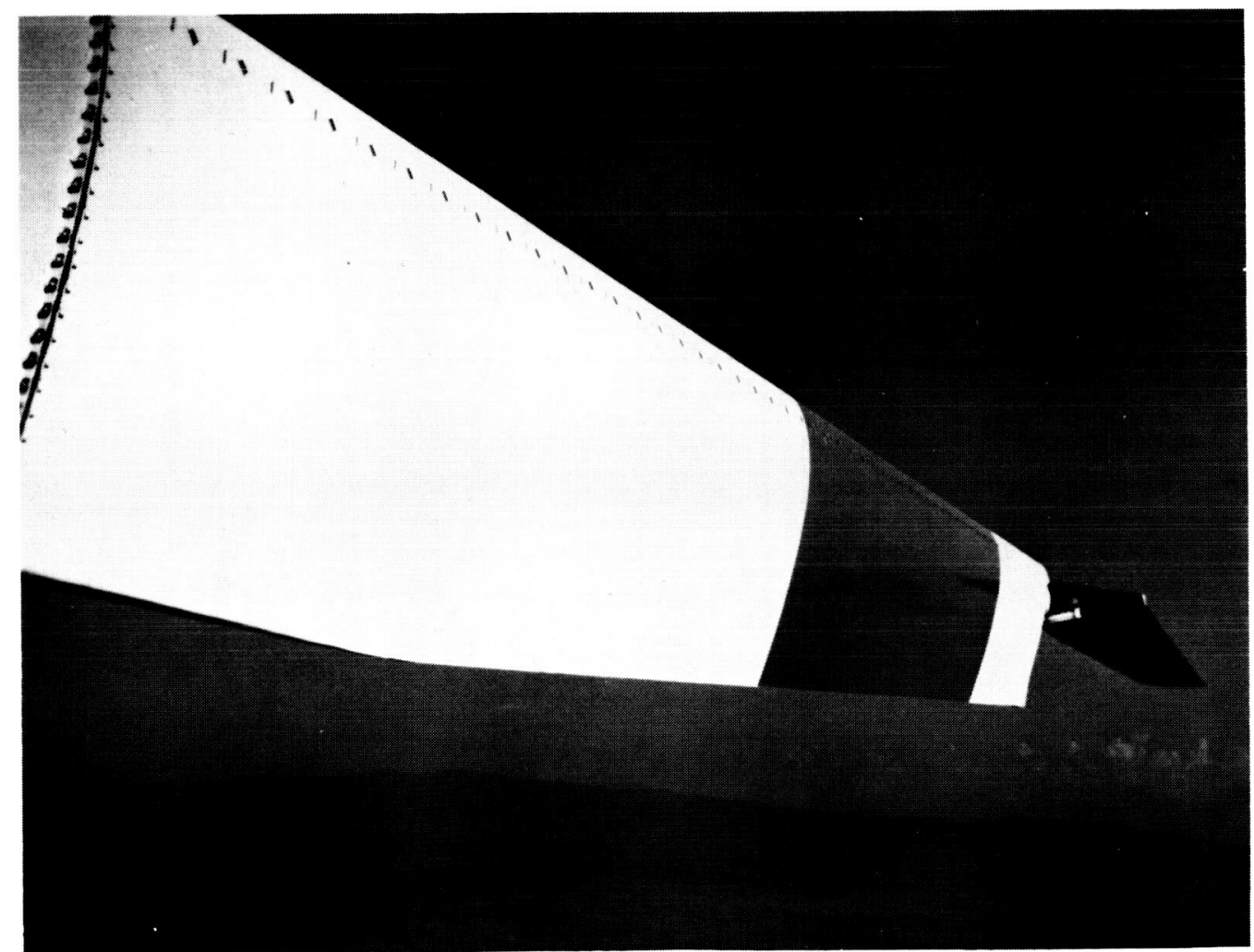

(B) VORTEX GENERATORS MOUNTED ON MOD-2 ROTOR.

Figure 4. - PHOTOGRAPHS OF VORTEX GENERATORS USED IN MOD-2 TESTS (REPRODUCED FROM SULLIVAN 1984). 


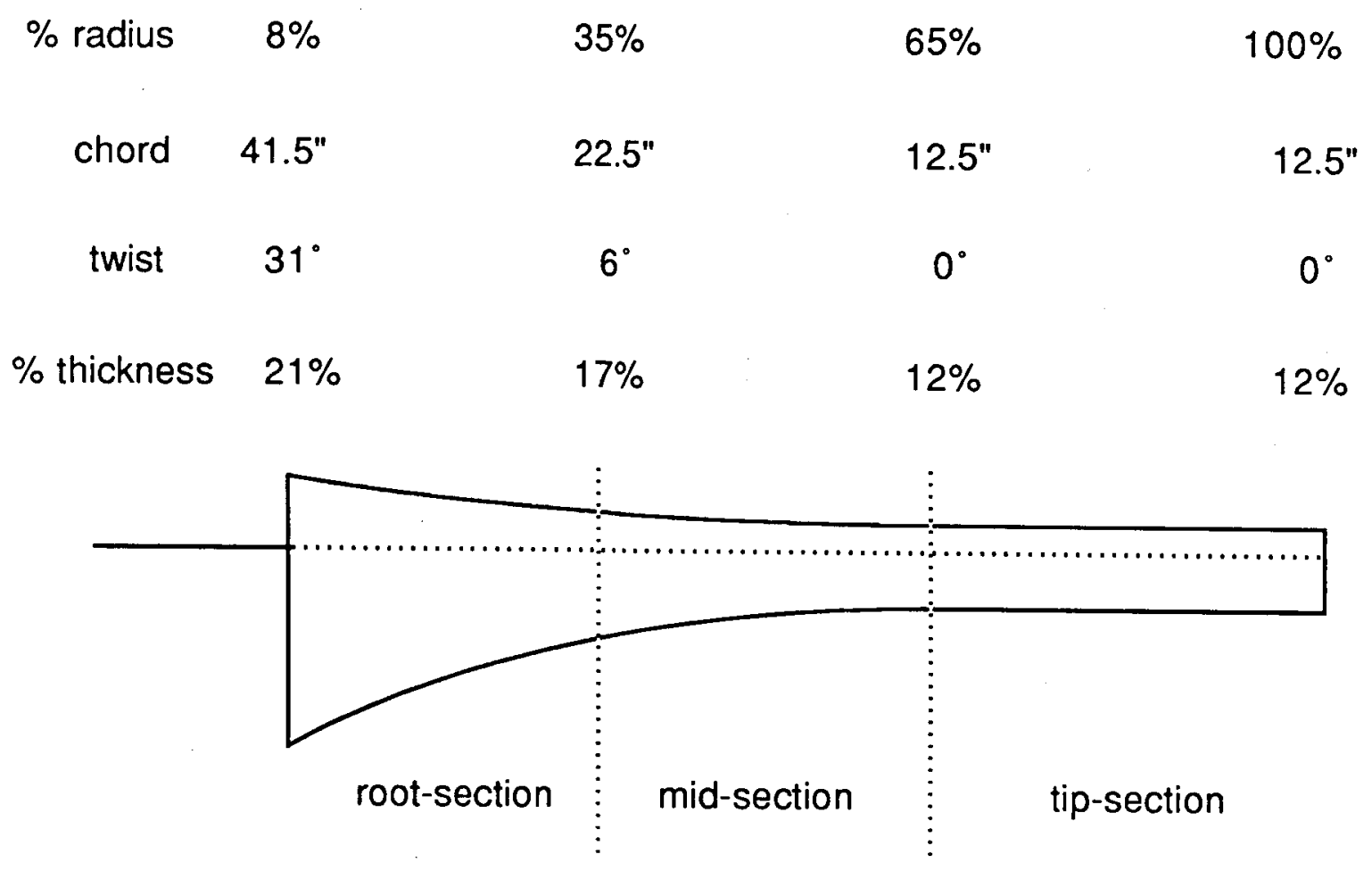

Figure 5. - Planform and blade sections of the Carter Model 25 ROTOR. 


\begin{tabular}{|c|r|r|r|r|r|r|}
\hline $\begin{array}{c}\text { Blade } \\
\text { section }\end{array}$ & $\begin{array}{c}\text { Mean } \\
\text { radius } \\
\text { (inches) }\end{array}$ & $\begin{array}{c}\text { Mean } \\
\text { chord } \\
\text { (inches) }\end{array}$ & $\begin{array}{c}\text { Mean } \\
\text { speed } \\
(\mathrm{ft} / \mathrm{sec})\end{array}$ & $\begin{array}{c}\text { Reynolds } \\
\text { number at } \\
\mathrm{x}=\mathrm{c} / 10\end{array}$ & $\begin{array}{c}\text { Approximate } \\
\text { laminar boundary } \\
\text { layer thickness } \\
\text { at } \mathrm{x}=\mathrm{c} / 10 \\
\mathrm{t} \text { inches })\end{array}$ & $\begin{array}{c}\text { Approximate } \\
\text { turbulent boundary } \\
\text { layer thickness } \\
\text { at } \mathrm{x}=\mathrm{c} / 10 \\
\text { (t, inches })\end{array}$ \\
ROOT & 620 & 131 & 95 & 655,000 & 0.057 & 0.332 \\
MID & 1,070 & 102 & 163 & 886,000 & 0.038 & 0.245 \\
TIP & 1,530 & 74 & 234 & 910,000 & 0.027 & 0.175 \\
\hline
\end{tabular}

NOTES: $\quad$ calculated using $t / x=3.50 \times(R e)$

$-1 / 2$

NOTES: 0 calculated using $U x=3.50 x(R e)$

† calculated using $t / x=0.37 \times(R e)$

TABLE 1. Mean specifications of MOD-2 turbine blades 


\begin{tabular}{|c|r|r|r|r|r|r|}
\hline $\begin{array}{c}\text { Blade } \\
\text { section }\end{array}$ & $\begin{array}{c}\text { Mean } \\
\text { radius } \\
\text { (inches) }\end{array}$ & $\begin{array}{r}\text { Mean } \\
\text { chord } \\
\text { (inches) }\end{array}$ & $\begin{array}{c}\text { Mean } \\
\text { speed } \\
(\mathrm{ft} / \mathrm{sec})\end{array}$ & $\begin{array}{c}\text { Reynolds } \\
\text { number at } \\
\mathrm{x}=\mathrm{c} / 10\end{array}$ & $\begin{array}{c}\text { Approximate } \\
\text { laminar boundary } \\
\text { layer thickness } \\
\text { at } \mathrm{x}=\mathrm{c} / 10 \\
(\mathrm{t}, \mathrm{inches})\end{array}$ & $\begin{array}{c}\text { Approximate } \\
\text { turbulent boundary } \\
\text { layer thickness } \\
\text { at } \mathrm{x}=\mathrm{c} / 10 \\
(\mathrm{t}, \text { inches })\end{array}$ \\
\hline ROOT & 41.5 & 32.0 & 43.5 & 73,000 & 0.041 & 0.126 \\
MID & 96.8 & 17.5 & 101.4 & 94,000 & 0.020 & 0.066 \\
TIP & 158.8 & 12.5 & 166.3 & 110,000 & 0.013 & 0.045 \\
\hline
\end{tabular}

NOTES: $\quad 0$ calculated using $t / x=3.50 \times(R e)$

$-1 / 2$

$\dagger$ calculated using $t / x=0.37 \times(R e)^{-1 / 5}$

TABLE 2. Mean specifications of Carter Model 25 turbine blades 


\begin{tabular}{|c|c|c|c|c|c|}
\hline $\begin{array}{c}\text { Blade } \\
\text { section }\end{array}$ & $\begin{array}{c}\text { VG height } \\
(\mathrm{H}, \text { inches) }\end{array}$ & $\begin{array}{c}\text { VG lengtht } \\
\text { (L, inches) }\end{array}$ & $\begin{array}{c}\mathrm{H} / \mathrm{t} \\
\text { (laminar) }\end{array}$ & $\begin{array}{c}\mathrm{H} / \mathrm{t} \\
\text { (turbulent) }\end{array}$ & L/chord \\
\hline ROOT & 0.80 & 3.2 & 14.0 & 2.4 & 0.024 \\
MID & 0.63 & 2.5 & 16.4 & 2.6 & 0.025 \\
TIP & 0.25 & 1.0 & 9.3 & 1.4 & 0.014 \\
\hline
\end{tabular}

NOTE: $\quad$ $L H=4$

TABLE 3. Sizes of vortex generators tested on MOD-2 turbine 
approximation, the root- and mid-sections obey both geometric and boundary layer scaling while the tip-section vortex generators are about half the size predicted by these laws.

The next step in the design process was to apply these ratios to the design of vortex generators for the Carter blades. Table 4 shows the results of this procedure using a vortex generator length to blade chord ratio of $1 / 40$ for all three sections. The resulting vortex generators are relatively smaller with respect to boundary layer height than for the MOD-2 by an average factor of about 2 . It is also noted however that these vortex generators still extend significantly into the free stream flow, particularly if the boundary layer thickness approximates to the laminar value. It is therefore reasonable to use these sizes as a basis for a first design.

Because of the large number required for the tests, and in order to minimize costs, it was decided to use readily available material sizes for construction of the vortex generators. Small angle section was selected in order to facilitate attachment to the blade surface. The closest approximations to the design heights of table 4 were the two smallest sizes of brass angle available in model/hobby stores, namely $24 \mathrm{AWG}, 1 / 8^{\prime \prime} \times 1 / 8$ " and $3 / 16^{\prime \prime} \times 3 / 16^{\prime \prime}$. The sizes of the resulting vortex generators are shown in table 5. While these material sizes matched the design sizes well for the root- and mid-sections, the lower size limit forced the tip-section vortex generators to be as large as the mid-section devices. While this produces a vortex generator length to blade chord ratio even farther from the MOD-2 case, the height to boundary layer thickness ratio was now a better approximation. Following the MOD-2 designs, an aspect ratio of 1/4 was used for the vortex generators in all cases.

\section{- Location and orientation of vortex generators}

The location and orientation of the vortex generators for the Carter was determined using a straightforward geometric scaling from the MOD-2 design on the basis of blade chord. All vortex generators were located at $10 \%$ of the local chord from the leading edge and were arranged in a counterrotating pattern with an angle of incidence of $20^{\circ}$. The layout of vortex generators is shown in figure 6 . The spacing parameters $\mathrm{d}$, the pair width, and $\mathrm{D}$, the pair spacing, are also defined in figure 6 . In the MOD-2 tests, for each spanwise section, the spacing parameter ratio D/d was a consistent 1.5 with a pair width, $\mathrm{d}, 1 / 10$ of the mean chord. (It should be noted that, in this and other studies, a pair of vortex generators arranged in a counterrotating pattern is defined as two adjacent devices having their trailing edges closer than their leading edges). This same scaling was used for the design of vortex generators for the Carter blades, so that although the mid-and tip-section vortex generators were the same size, the tip-section vortex generators were placed closer together because of the smaller mean chord size.

A complete definition of the tested vortex generator configurations for each of the three spanwise sections are summarized in table 6. 


\begin{tabular}{|c|c|c|c|c|c|}
\hline $\begin{array}{c}\text { Blade } \\
\text { section }\end{array}$ & $\begin{array}{c}\text { VG height } \\
(\mathrm{H}, \text { inches) }\end{array}$ & $\begin{array}{c}\text { VG lengtht } \\
(\mathrm{L} \text {, inches) }\end{array}$ & $\begin{array}{c}\mathrm{H} / \mathrm{t} \\
\text { (laminar) }\end{array}$ & $\begin{array}{c}\mathrm{H} / \mathrm{t} \\
\text { (turbulent) }\end{array}$ & L/chord \\
\hline ROOT & 0.200 & 0.80 & 4.9 & 1.6 & 0.025 \\
MID & 0.109 & 0.44 & 5.5 & 1.7 & 0.025 \\
TIP & 0.078 & 0.31 & 6.0 & 1.7 & 0.025 \\
\hline
\end{tabular}

NOTES: $\diamond$ determined using $\mathrm{L} / \mathrm{H}=4$

$\dagger$ determined using L/chord $=0.025$

TABLE 4. Design sizes of vortex generators for Carter Model 25 turbine 


\begin{tabular}{|c|c|c|c|c|c|}
\hline $\begin{array}{c}\text { Blade } \\
\text { section }\end{array}$ & $\begin{array}{c}\text { VG height } \\
(\mathrm{H}, \text { inches })\end{array}$ & $\begin{array}{c}\text { VG lengtht } \\
\text { (L, inches) }\end{array}$ & $\begin{array}{c}\mathrm{H} / \mathrm{t} \\
\text { (laminar) }\end{array}$ & $\begin{array}{c}\mathrm{H} / \mathrm{t} \\
\text { (turbulent) }\end{array}$ & L/chord \\
\hline ROOT & 0.188 & 0.75 & 4.6 & 1.5 & 0.023 \\
MID & 0.125 & 0.50 & 6.3 & 1.9 & 0.029 \\
TIP & 0.125 & 0.50 & 9.6 & 2.8 & 0.040 \\
\hline
\end{tabular}

NOTE: + using $\mathrm{L}=4 \mathrm{H}$

TABLE 5. Sizes of vortex generators tested on Carter Model 25 turbine 

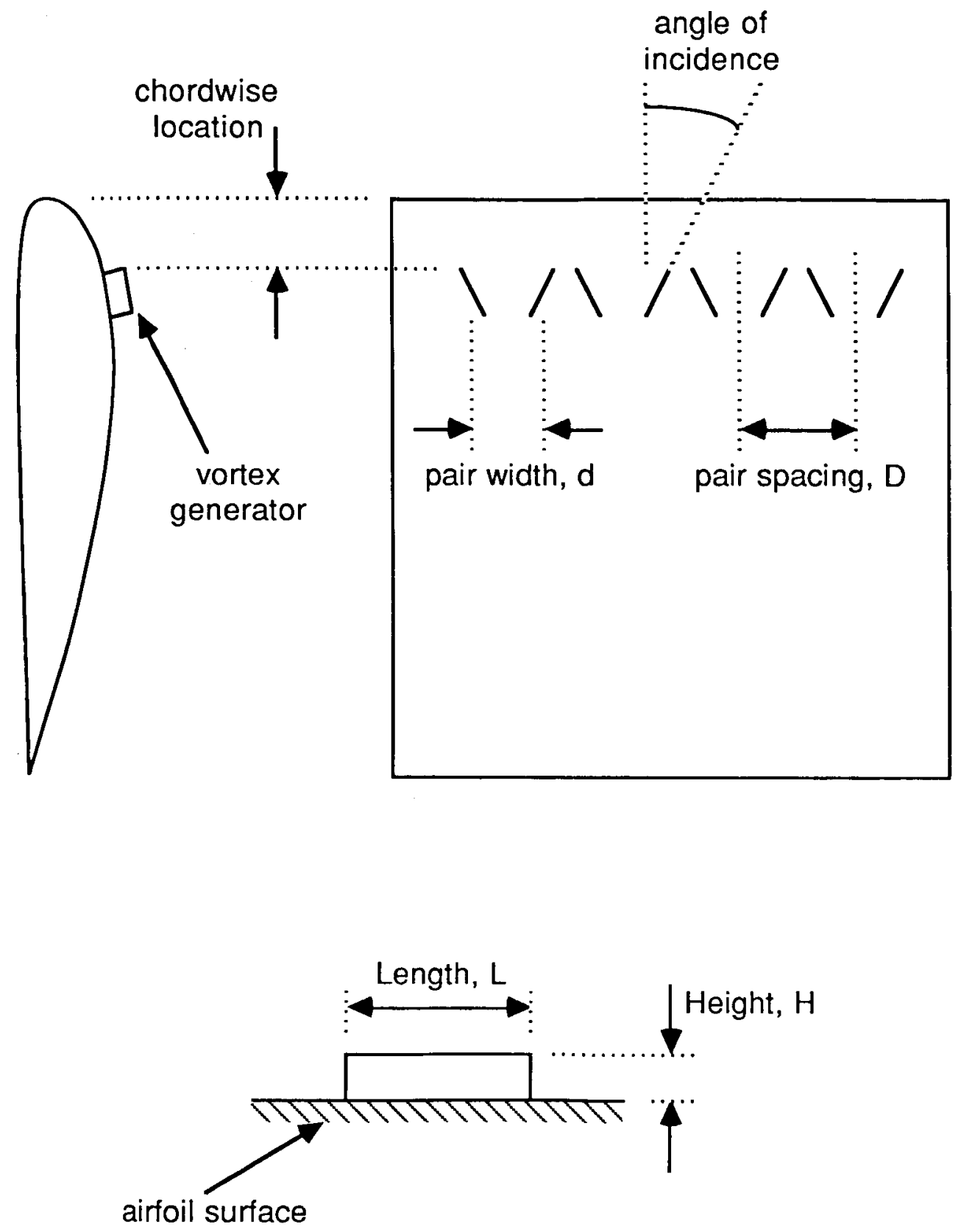

Figure 6. - PARAMEters defining Vortex generator CONF I GURAT IONS. 


\begin{tabular}{|c|c|c|c|c|}
\hline $\begin{array}{c}\text { Blade } \\
\text { section }\end{array}$ & $\begin{array}{c}\text { VG height } \\
(H, \text { inches })\end{array}$ & $\begin{array}{c}\text { VG length } \\
(L, \text { inches })\end{array}$ & $\begin{array}{c}\text { Pair width } \\
\text { ( } d \text {, inches })\end{array}$ & $\begin{array}{c}\text { Pair spacing } \\
(\mathrm{D}, \text { inches })\end{array}$ \\
\hline ROOT & 0.188 & 0.75 & 3.20 & 4.80 \\
MID & 0.125 & 0.50 & 1.75 & 2.63 \\
TIP & 0.125 & 0.50 & 1.25 & 1.88 \\
\hline
\end{tabular}

NOTE: All vortex generators were mounted at a distance of $10 \%$ of the local blade chord from the leading edge at an angle of incidence of $20^{\circ}$

TABLE 6. Complete definition of vortex generator configurations tested on Carter Model 25 turbine 


\section{- Leading edge roughness effects}

In figure 7 AeroVironment's rotor performance prediction model, PROP, has been used to estimate the effect of changes in pitch angle on the power curve of the Carter Model 25. It can be seen that a simple increase in pitch angle produces an effect very similar to that expected from the addition of vortex generators, although the exact shape of the curves will be slightly different. Both modifications tend to produce a substantial increase in output in high winds by delaying the onset of stall, with only a small decrease in pre-rated performance.

Instead of a simple increase in power output, the greatest value of vortex generators may therefore be in reducing the sensitivity of turbine performance to the effects of dirt and bugs which accumulate along the leading edge of operating blades. This leading edge roughness can causes premature boundary layer transition and flow separation at lower angles of attack than on a clean blade. This is currently a significant problem on several types of operating machines; the reduction in performance is sufficiently large for some windfarm operators to include blade washing as often as every two weeks on their maintenance schedule. This task involves considerable time and expense even for the Carter machine which has the advantage that it can be lowered or raised for ease of access in only a few minutes.

Therefore, if the vortex generator designs proposed in the previous section proved to be successful, rather than trying to optimize the shape, size and location of a set of vortex generators for the particular case of the Carter Model 25, it was decided that the final part of this study should maintain broad application and make a preliminary investigation into whether vortex generators can reduce the sensitivity of turbine performance to dirt and bugs on the leading edge. The main difficulty in this experiment was producing the "right" amount of roughness. It was decided to test the vortex generators with a relatively large amount of roughness to represent a "worst case" scenario, simulating dirt and bug accumulation over a long period; if the vortex generators alleviated the reduction in performance for such a severe case, they could also be expected to improve production on cleaner blades.

Abbott and von Doenhoff (1959) record that "the standard leading edge roughness selected by the NACA for 24" chord airfoil models consisted of 0.011 " Carborundum grains applied to the surface of the model at the leading edge over a surface length of $8 \%$ chord measured from the leading edge on both sides", and with "the grains thinly spread to cover 5-10\% of the area". The size of these grains is therefore about $1 / 2000$ of the airfoil chord. It is noted that theoretically roughness height should scale with boundary layer thickness for proper similarity in a way like that of vortex generator height. For two airfoils at the same Reynolds number, then, roughness height should scale with chord. Using a geometric scaling based on blade chord, the equivalent standard leading 


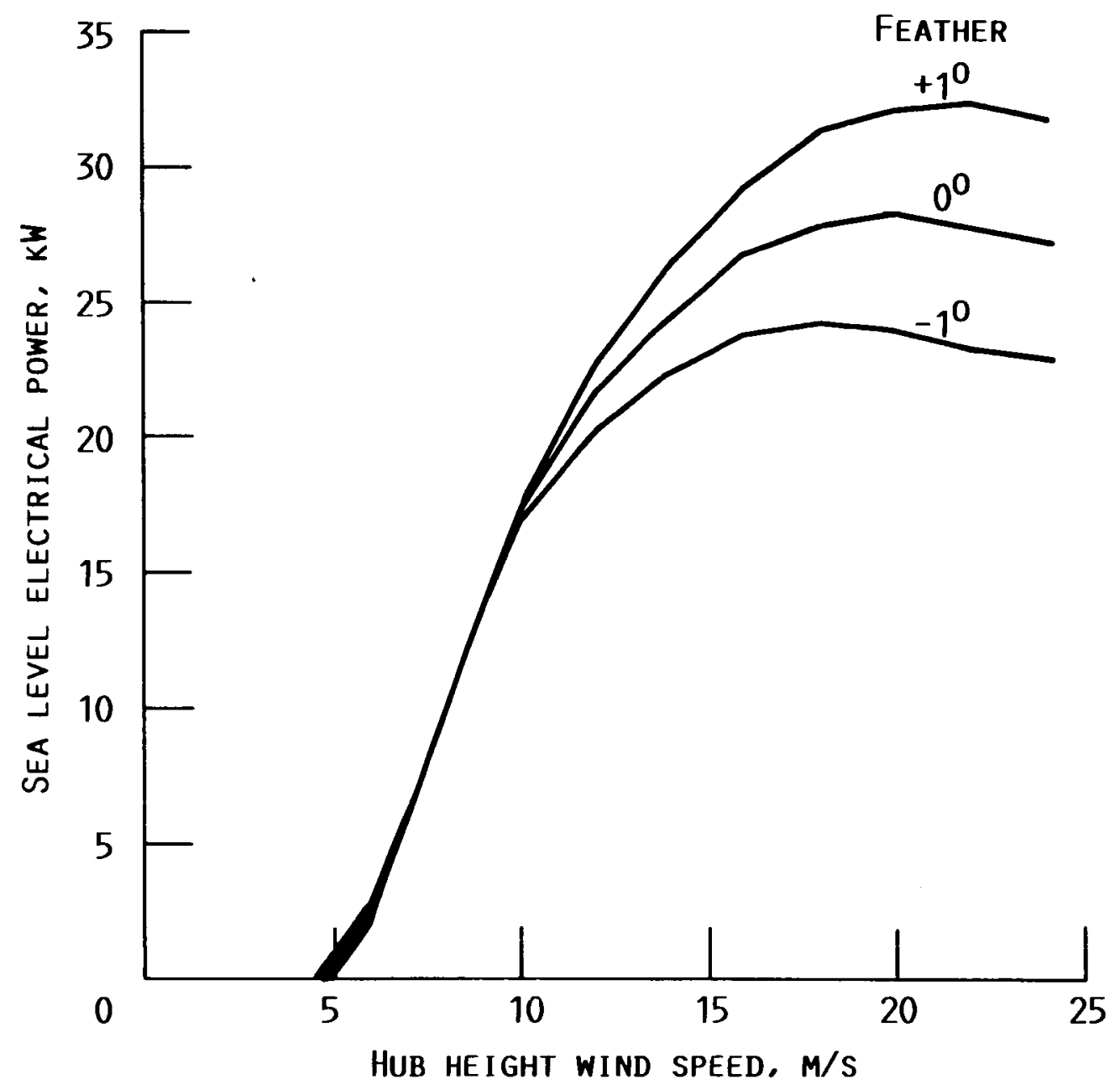

FIgURE 7.- EFFECT OF FEATHER ANGLE ON THE PERFORMANCE OF THE CARTER MODEL 25 TURBINE AS PREDICTED BY THE PROP CODE. 
edge roughness for the tip-section of the Carter blades would consist of 0.006" grains covering a strip 2" wide centered on the leading edge. It was noted during the field tests that bugs and dirt tended to accumulate only over about a 1" wide strip at the leading edge on the outboard half of the blade and that the type of particles ranged from fine desert sand and dust to relatively large pieces of insect with sizes up to about $1 / 20^{\prime \prime}$. In order to ensure that the field test was carried out for a worst case scenario, a 1" wide strip of 36 grit sandpaper ( 0.028 " grain size) was used on the outboard 66" of the blade. It is noted that these particles are about 4 times larger than the equivalent NACA standard. 


\section{FIELD TEST}

The field test program was carried out during the period from August 1985 to February 1986 on one of the Carter Model 25 wind turbines in a windfarm managed by San Gorgonio Farms Inc. in San Gorgonio Pass, California. The terrain at the site is essentially flat with a slight slope downwards towards the south-southeast of about $1: 30$. The test turbine was located at the extreme southwest corner of the array; since the prevailing wind direction is westerly, this selection would avoid wake interference from other turbines as much as possible and at the same time keep the study out of the way of access roads and maintenance operations. A photograph of the test site is shown in figure 8 , the test turbine is nearest the camera in the center of the picture.

The effect of the vortex generators was studied by measuring the power curve of each of the following configurations:

1) base line (no vortex generators)

2) vortex generators on the inboard half of each blade

3) vortex generators on the outboard half of each blade

4) vortex generators on the entire span of each blade

5) vortex generators on the outboard half of each blade with leading edge roughness on the outer $66^{\prime \prime}$

6) leading edge roughness only on the outboard 66" of each blade

7) repeat of base line

Each configuration was tested in turn for about two weeks. Both the vortex generators and the leading edge roughness strips were attached to the blade using contact cement. Figure 9 shows one of the blades in configuration 4. The larger vortex generators used on the root-section can be clearly distinguished from the smaller size on the mid- and tip-sections. The number of data points collected and run hours for each configuration is shown in table 7.

AeroVironment's portable data acquisition system for wind turbine performance monitoring was used to collect data on each of the configurations tested. The system, based on a Compaq computer, is described in detail by Gyatt and Lissaman (1985). Basically it samples power output and three orthogonal components of wind speed approximately every 2.4 seconds, and air temperature and pressure every 24 seconds. This data is averaged over four minute periods and a bin sort performed to produce an equivalent power curve at standard sea level conditions. Each bin is $1.0 \mathrm{~m} / \mathrm{s}$ wide and the standard error of each bin average is computed to quantify the certainty associated with that value. The error bars on the following graphs show the magnitude of one standard deviation for each point. This error is typically only a fraction of a $\mathrm{kW}$ giving a high degree of confidence in the accuracy of the resulting power curve. This level of confidence is supported by the observation that the power curves obtained are all smooth - an expected characteristic of a real machine. 


\section{CaGHal PAGE IS \\ OF POOR QUALTTY}

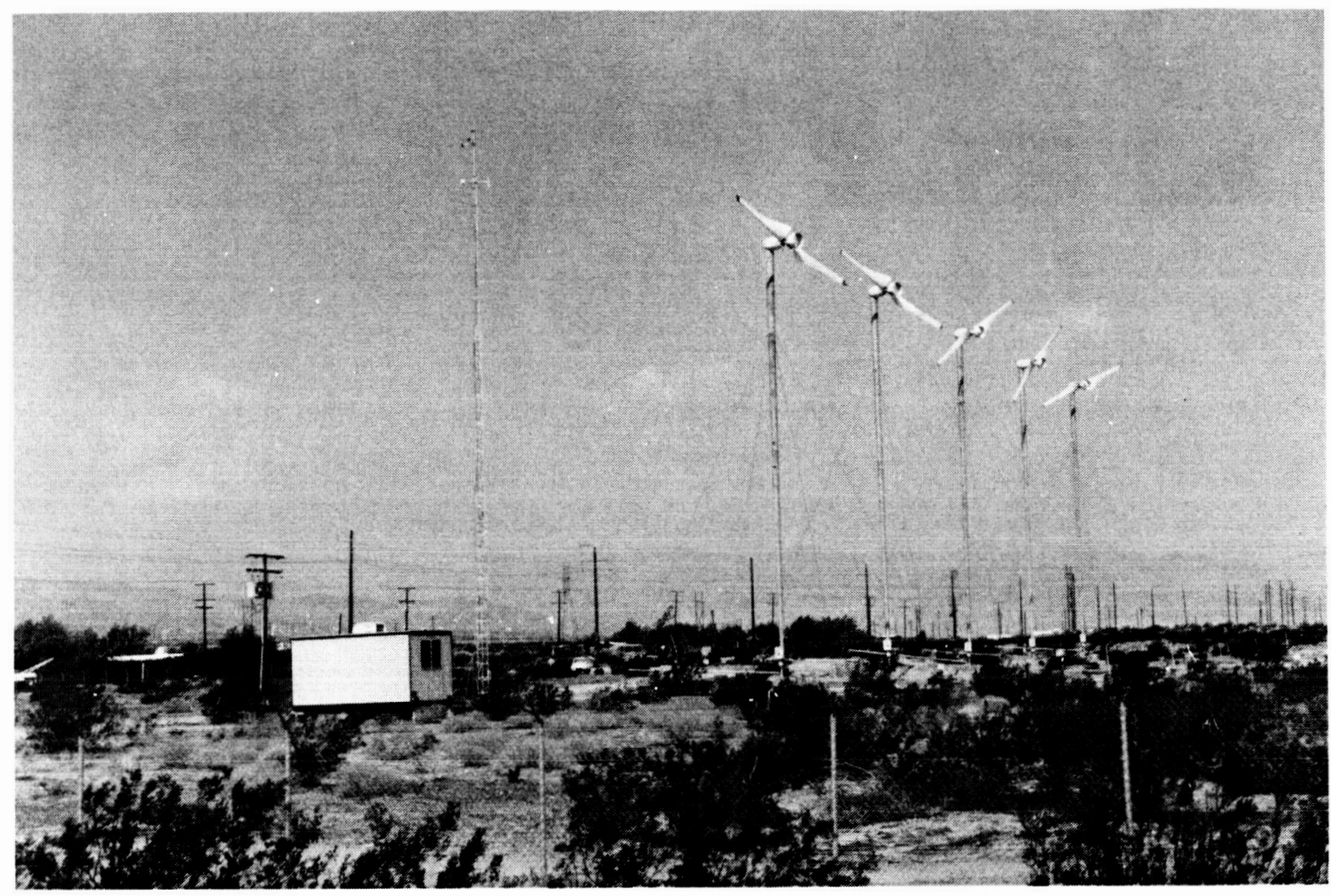

FigURE 8. - FIELD TEST SITE LOOKING NORTHWEST. 


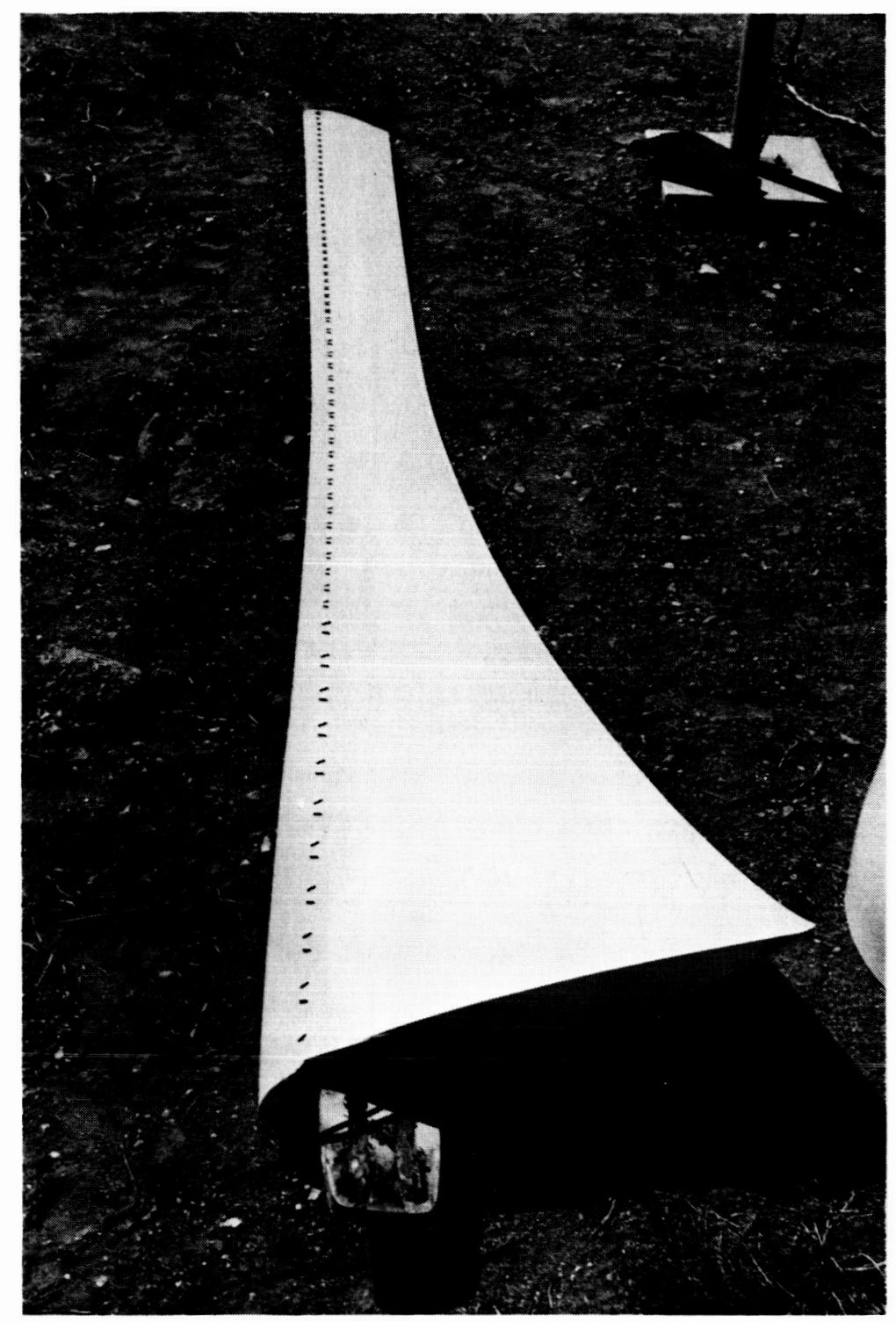

Figure 9. - Carter Model 25 Blade ReAdy for FULL SPAN COVERAGE TESTS (CONFIGURATION 4). 


\begin{tabular}{|c|c|c|c|}
\hline \multirow{2}{*}{ Configuration } & \multirow{2}{*}{ Description } & \multicolumn{2}{|c|}{ Quantity of data } \\
\hline & & No. readings & No. hours \\
\hline $\begin{array}{l}1 \\
2 \\
3 \\
4 \\
5 \\
6 \\
7 \\
1+7\end{array}$ & $\begin{array}{l}\text { Pre-test baseline } \\
\text { VGs on root half span } \\
\text { VGs on tip half span } \\
\text { VGs on full span } \\
\text { Leading edge roughness }+ \text { VGs on tip half span } \\
\text { Leading edge roughness on tip half span } \\
\text { Post-test baseline } \\
\text { Baseline }\end{array}$ & $\begin{array}{l}280,000 \\
311,000 \\
385,000 \\
402,000 \\
377,000 \\
315,000 \\
140,000 \\
420,000\end{array}$ & $\begin{array}{r}187 \\
207 \\
257 \\
268 \\
251 \\
210 \\
93 \\
280\end{array}$ \\
\hline TOTAL & & $2,210,000$ & 1,473 \\
\hline
\end{tabular}

TABLE 7. Quantity of performance data collected for each configuration 


\section{DISCUSSION OF RESULTS}

Performance curves for the first four configurations described above are presented in figures 10 through 13. Figure 14 shows the post-test base line data while figure 15 compares the pre- and post-test base line data; unfortunately, the generator and brake assembly of the test turbine had to be replaced early in 1986 and it is believed that this change was at least partly responsible for the observed differences between the two curves. The only measurements taken after the turbine repair were those for configurations 6 and 7, and these results should therefore be treated with caution. Figure 16 compares the performance of configurations 2 through 4 with the pre-test base line curve. In every case, the vortex generators produced a performance improvement at wind speeds above 10 $\mathrm{m} / \mathrm{s}$ with only a minor performance degradation at lower wind speeds. The peak increase in power output was about $5 \mathrm{~kW}$ ( $20 \%$ of rated power) for the full span coverage configuration at wind speeds around $16 \mathrm{~m} / \mathrm{s}$. Comparison of the curves reveals that the contribution of the inboard or root half-span vortex generators is significantly smaller than that of the outboard or tip half-span vortex generators. This may be the result of a combination of three factors; first, the inboard half span represents only $1 / 4$ of the total swept area; second, the speeds seen by that part of the blade are relatively low which limits the amount of drag it can produce; third, despite the relatively large amount of twist built into the Carter blade (over $30^{\circ}$ root to tip), the inboard sections may be too deeply stalled at wind speeds above $10 \mathrm{~m} / \mathrm{s}$ for vortex generators to have any effect. In certain calses, therefore, the most cost effective way to use vortex generators may be to apply them only on the outboard parts of wind turbine blades leaving the inner sections untouched.

The performance of each configuration has been quantified further in terms of annual performance parameters in table 8 . Only at low wind speed sites would the vortex generators cause a net decrease in production; at high wind speed sites (18 mph annual average), the vortex generators can be expected to produce up to $8 \%$ more revenue, or about $\$ 20,000-\$ 30,000$ per year per installed MW.

First comparisons of data for configurations 5 and 6 with leading edge roughness indicated that the performance was actually worsened by vortex generators. However, when the data was scrutinized more carefully, it was found that each measured power curve improved slowly with time. Each configuration had been tested using new leading edge roughness elements in order to produce equivalent initial conditions, and post-test inspection revealed that a significant amount of grit was indeed lost during each test period, probably due to rain. It was therefore postulated that the gradual performance improvement was a direct result of a deterioration in the amount of leading edge roughness. The correct way to evaluate the effect of the vortex generators was therefore to compare only the first few days of data. Figure 17 shows such a comparison for the first two days of data collected for each configuration. This comparison indicates that the vortex generators did 


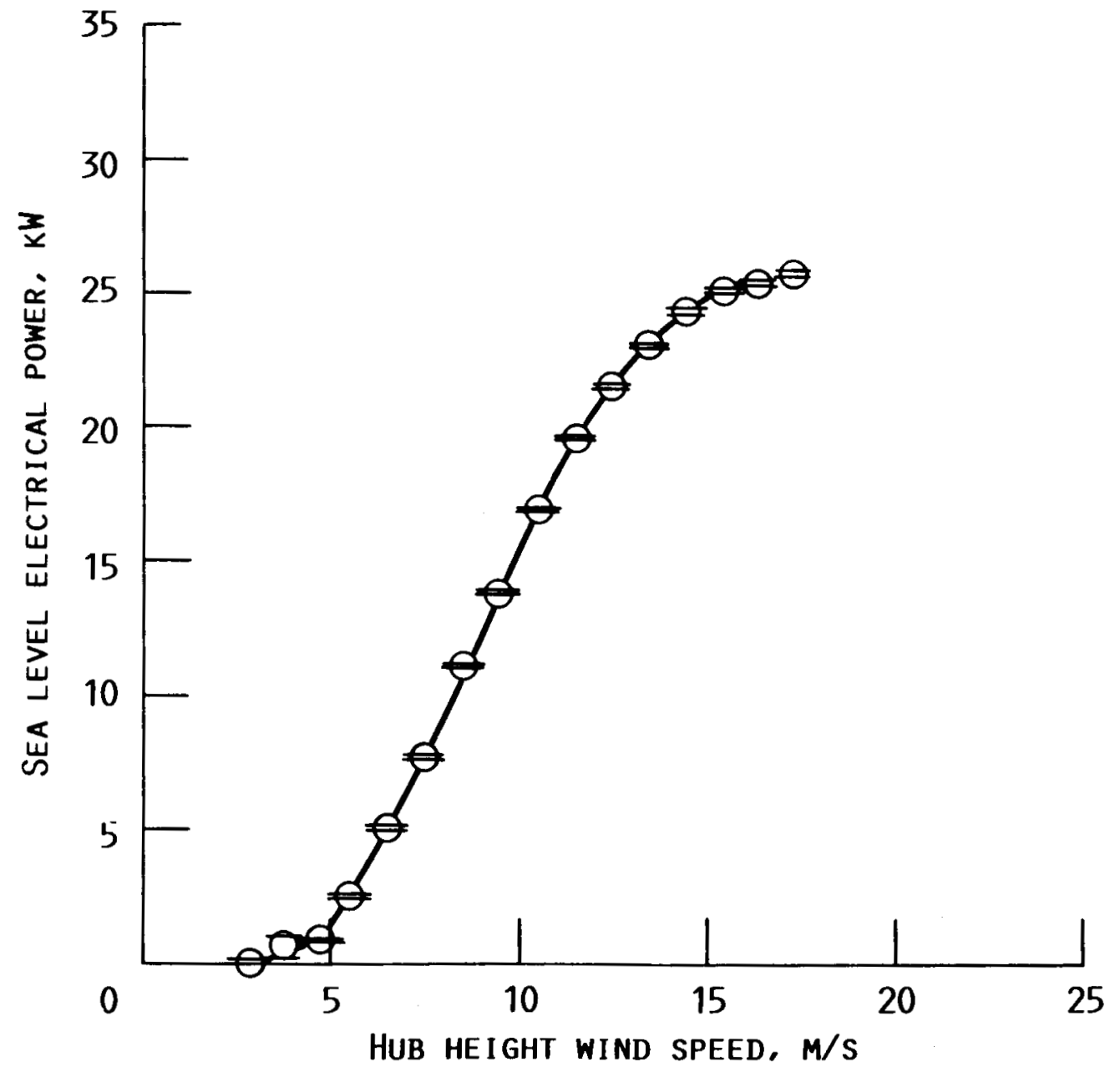

Figure 10.- MEASUREd PRE-TEst basel ine POWER CURVE (CONF I GURATION 1). 


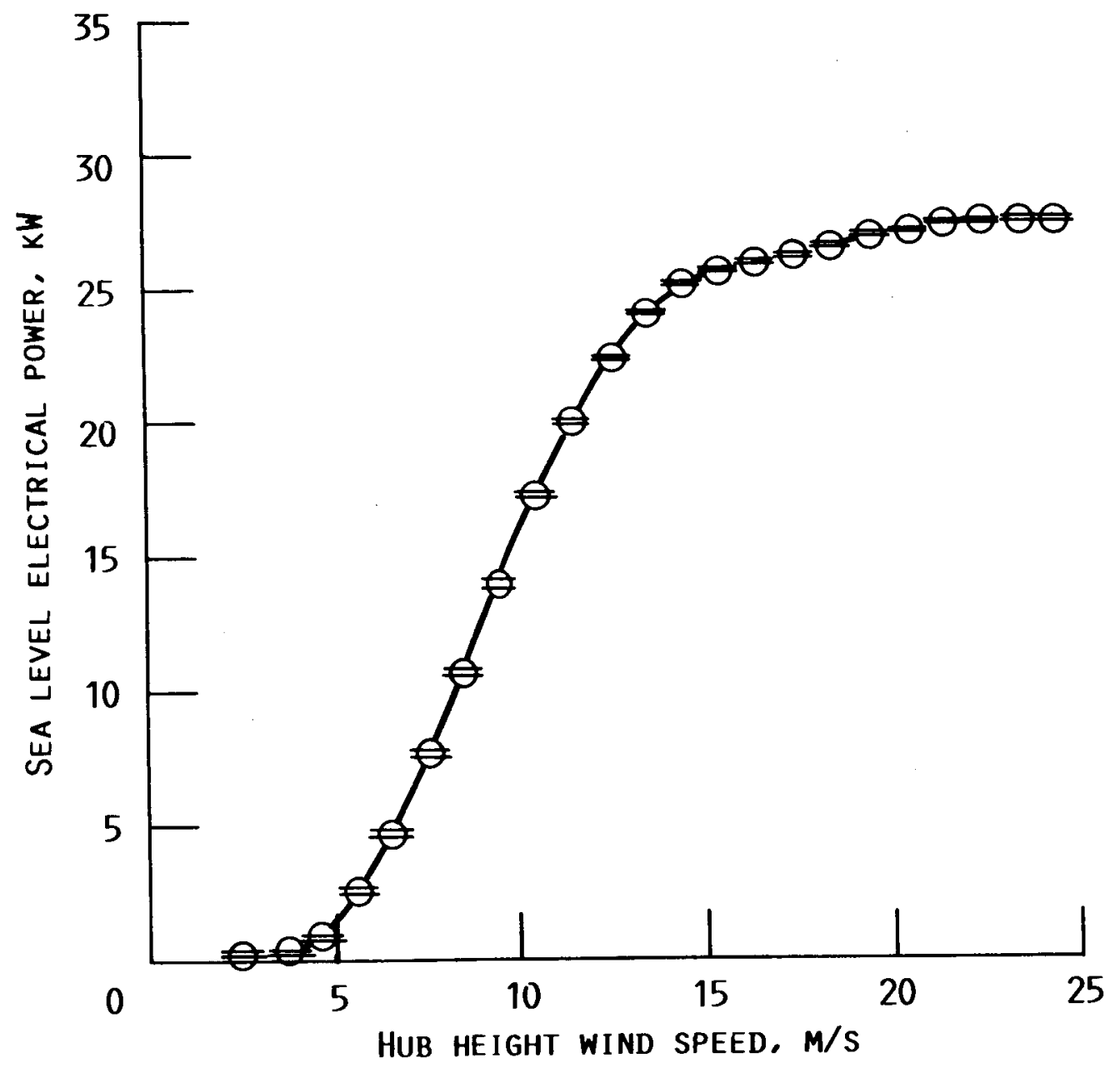

FigURE 11.- MEASURED POWER CURVE WITH VORTEX GENERATORS ON THE INBOARD HALF-SPAN (CONFIGURATION 2). 


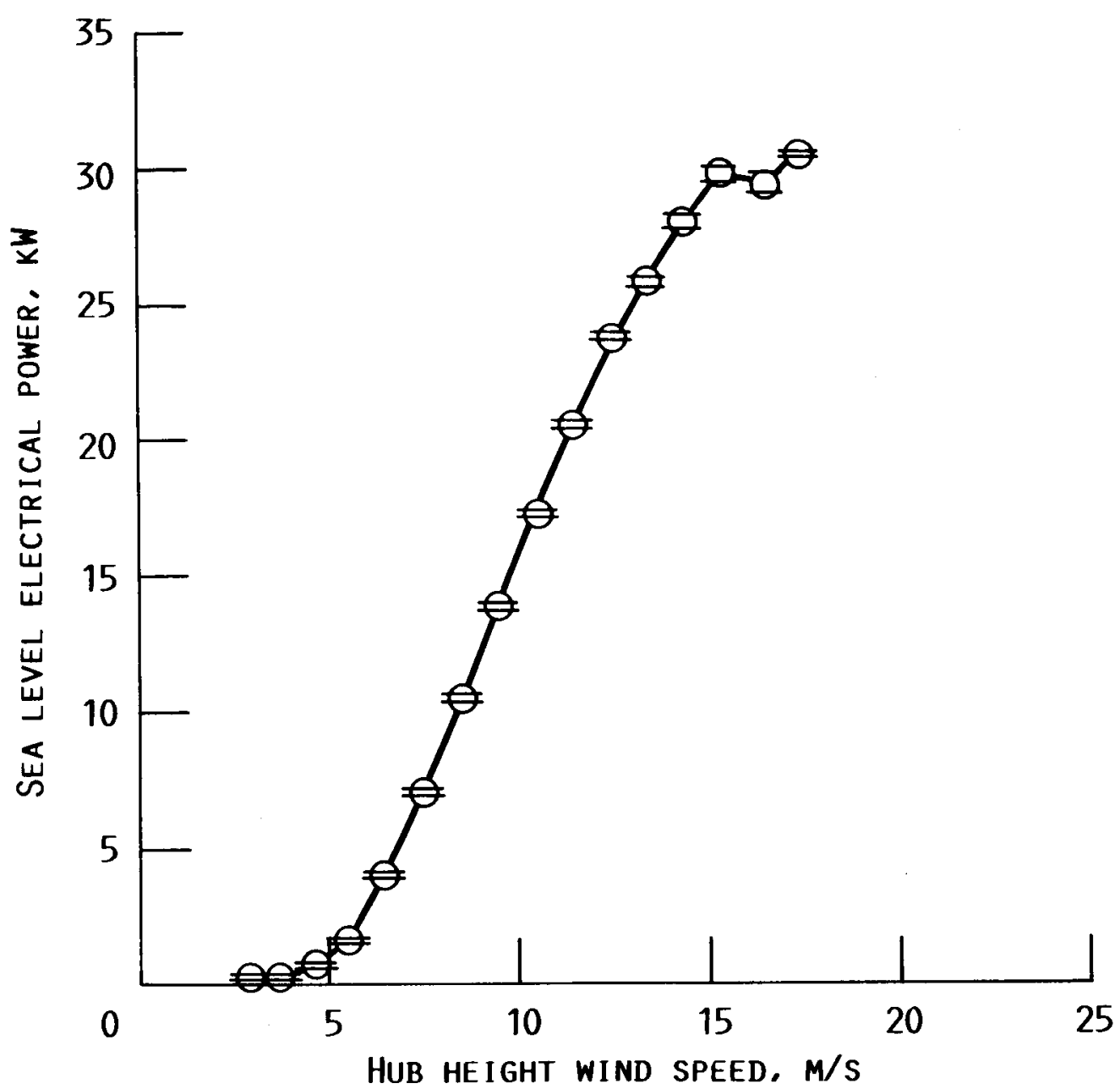

FIGURE 12.- MEASURED POWER CURVE WITH VORTEX GENERATORS ON THE OUTBOARD HALF-SPAN (CONFIGURATION 3 ). 


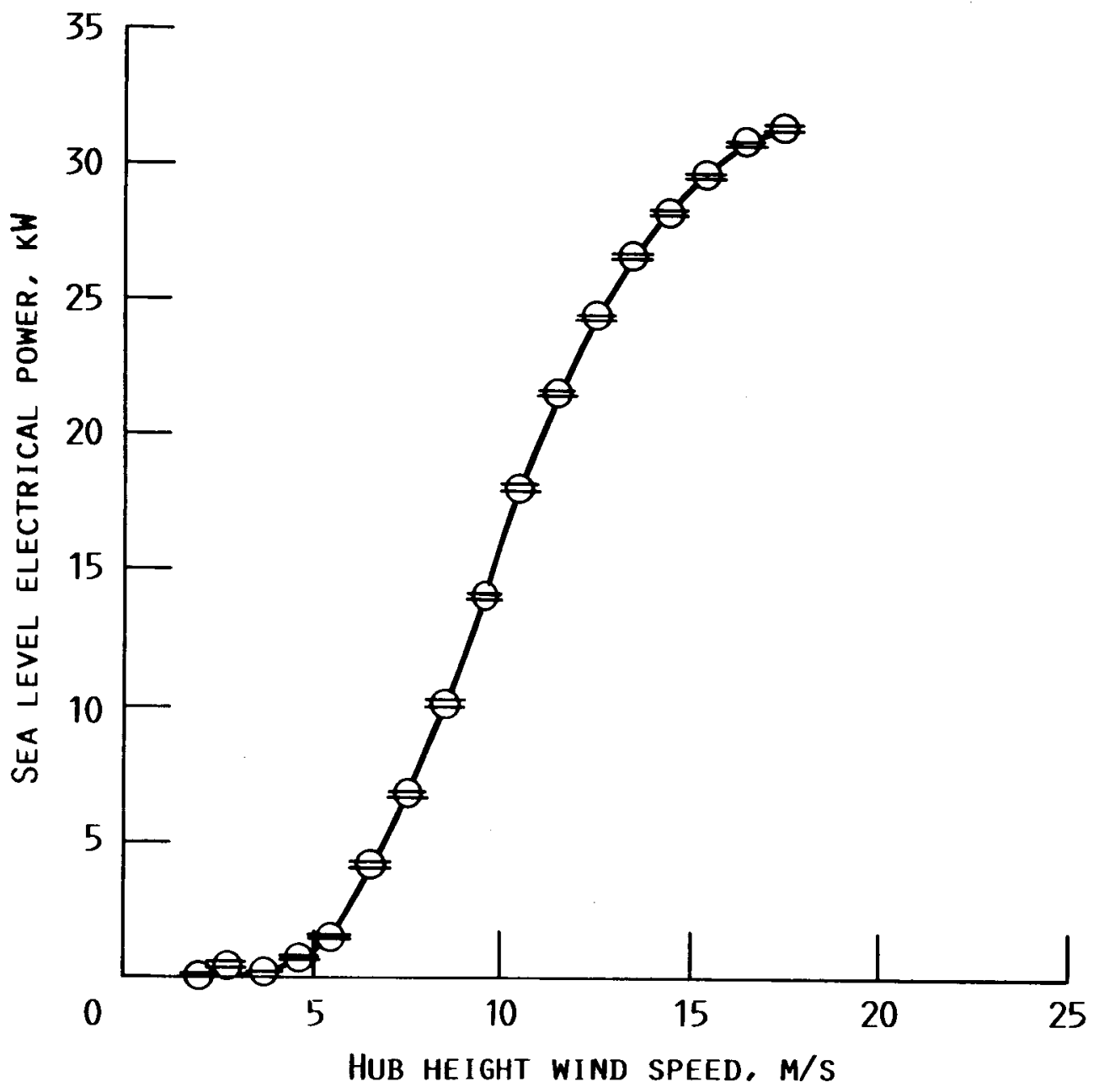

Figure 13. - MEASUREd POWER CURVE WITH VORTEX GENERATORS ON THE ENTIRE SPAN (CONFIGURATION 4). 


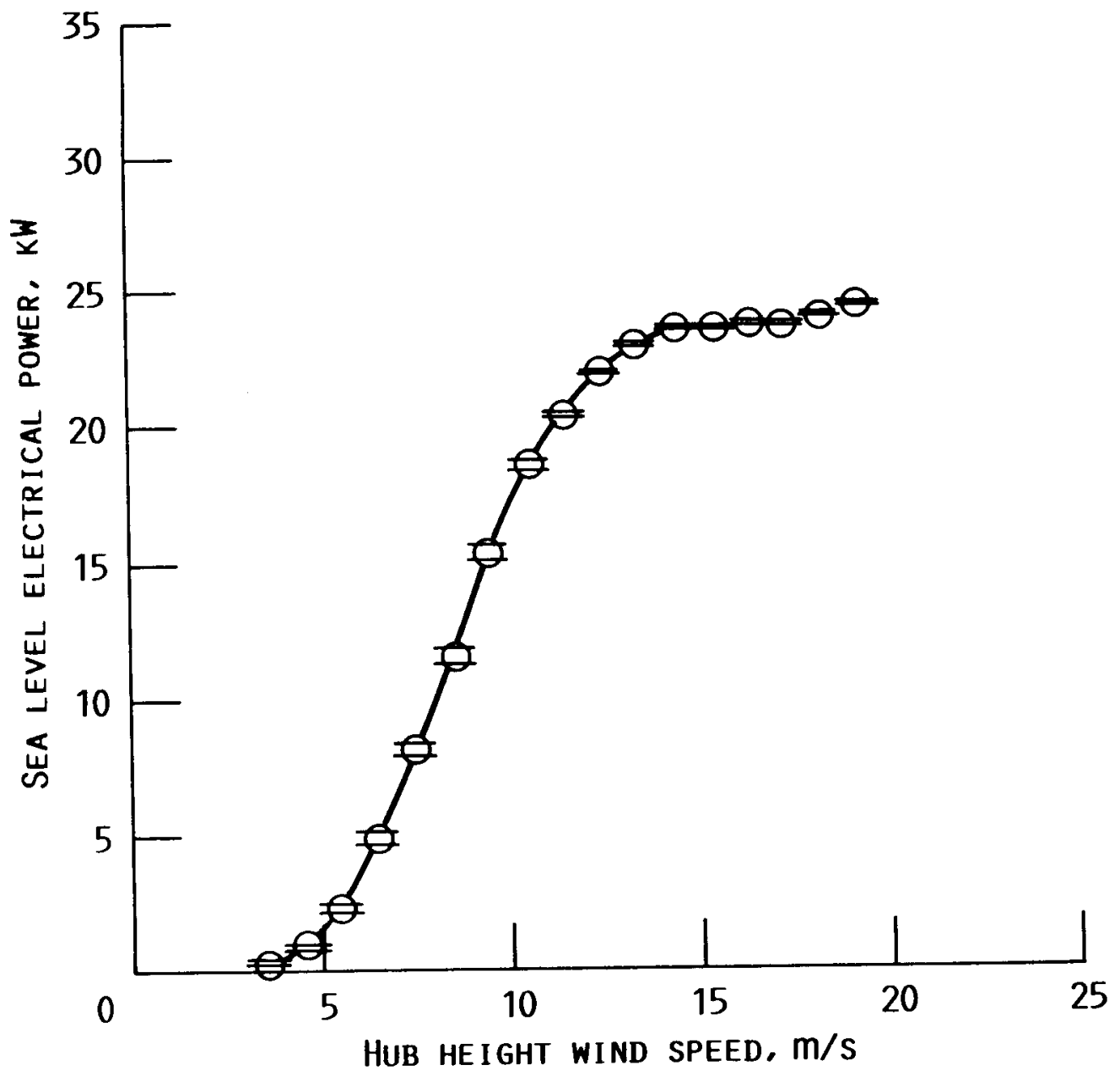

FigURE 14.- MEASURED POST-TEST BASEL INE POWER CURVE (CONFIGURATION 7). 


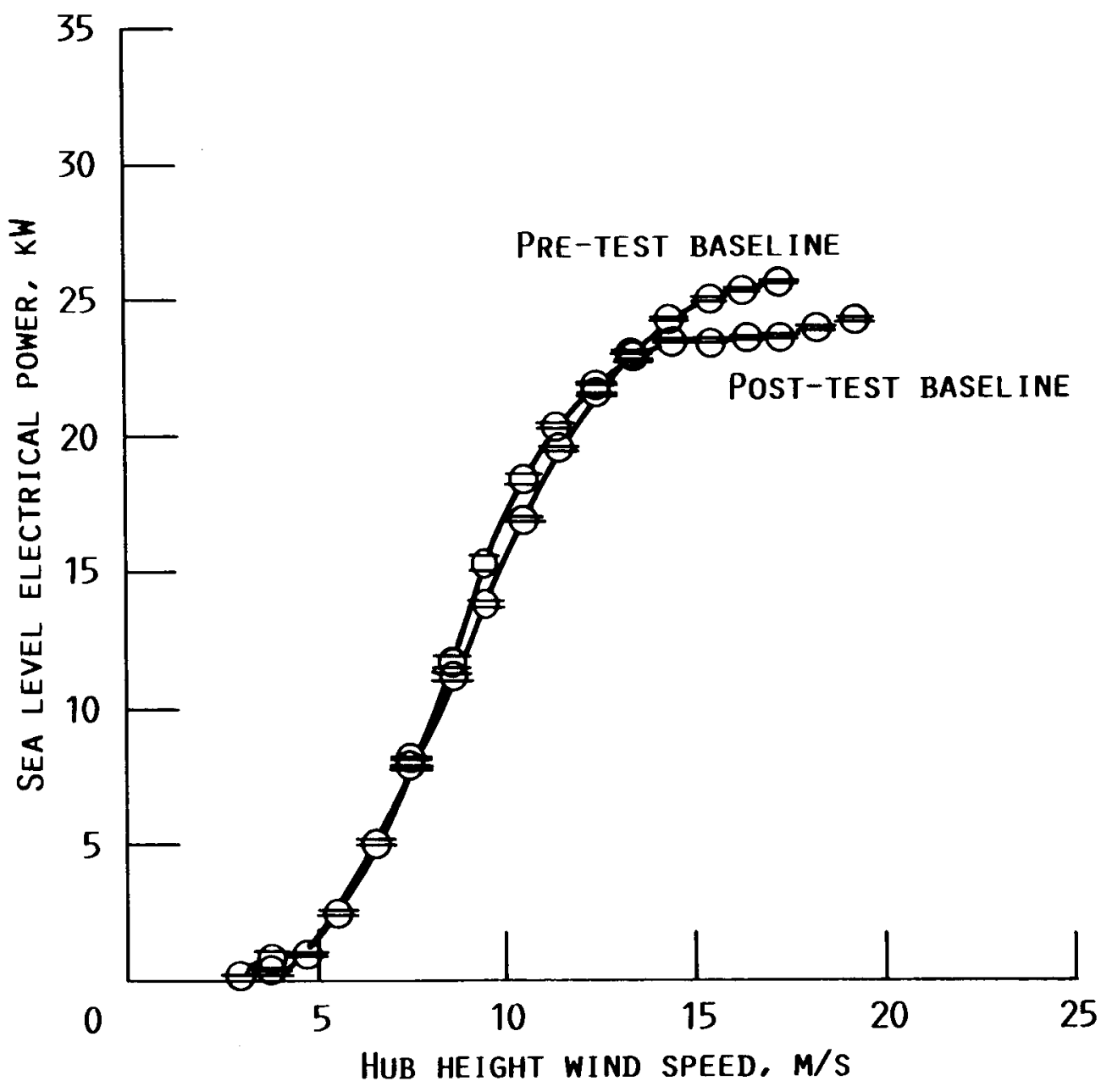

FIGURE 15. - COMPARISON OF PRE-AND POST-TEST BASELINE POWER CURVES (CONF I GURATIONS 1 AND 7 ). 


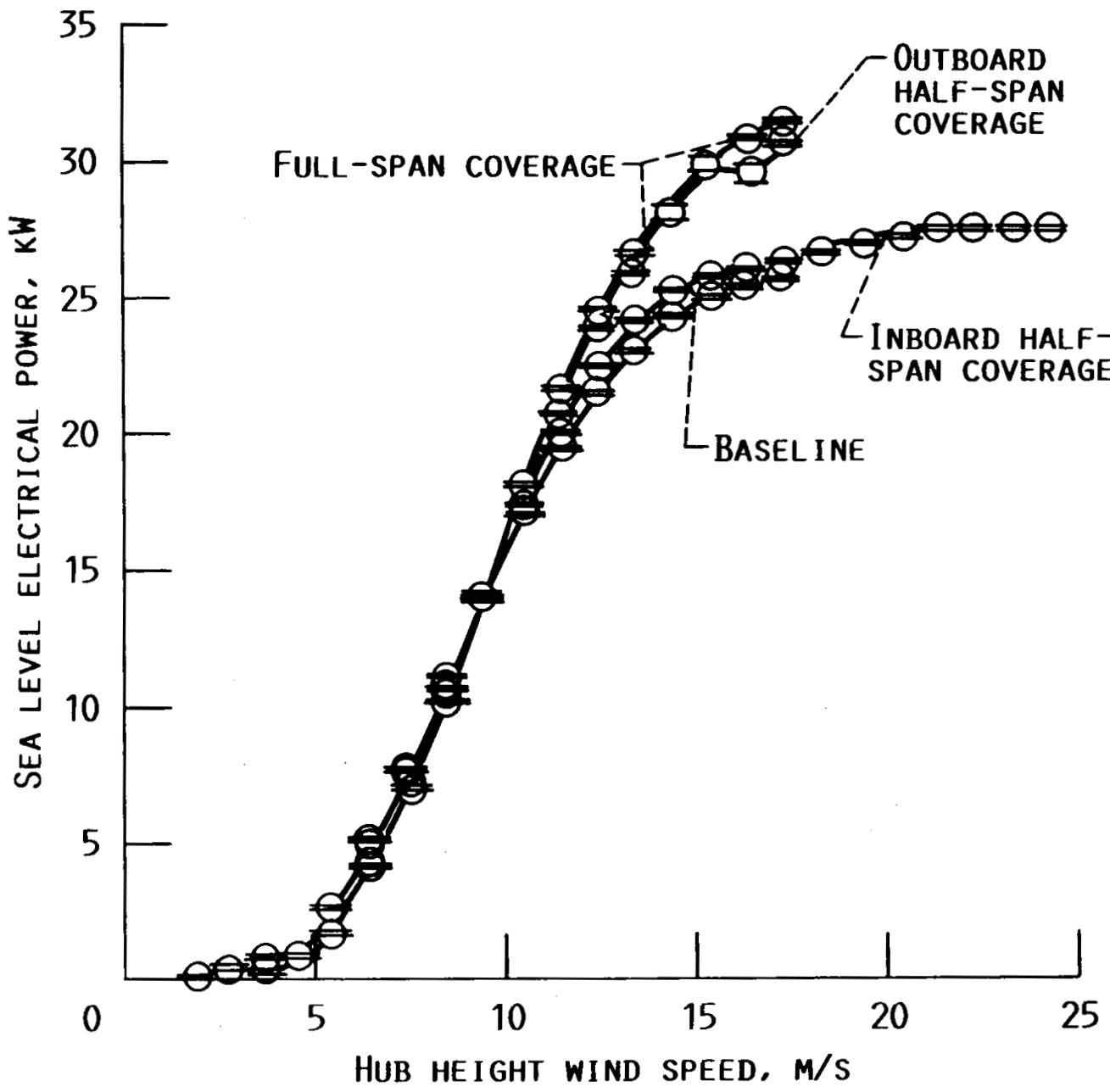

FIGURE 16.- EFFECT OF VORTEX GENERATORS ON MEASURED POWER CURVE. 


\begin{tabular}{|c|c|c|c|c|c|}
\hline $\begin{array}{c}\text { Mean wind } \\
\text { speedt(mph) }\end{array}$ & $\begin{array}{l}\text { Performance } \\
\text { parameter } 0\end{array}$ & $\begin{array}{c}\text { Baseline } \\
\text { configuration }\end{array}$ & $\begin{array}{l}\text { Root half-span } \\
\text { VG coverage }\end{array}$ & $\begin{array}{l}\text { Tip half-span } \\
\text { VG coverage }\end{array}$ & $\begin{array}{l}\text { Full span } \\
\text { VG coverage }\end{array}$ \\
\hline 12 & Mean power & 5.9 & 5.9 & 5.7 & 5.7 \\
\hline 14 & output (kW) & 8.0 & 8.1 & 8.1 & 8.2 \\
\hline 16 & & 10.0 & 10.2 & 10.5 & 10.6 \\
\hline 18 & & 11.8 & 12.0 & 12.6 & 12.8 \\
\hline 12 & Capacity & 0.23 & 0.23 & 0.23 & 0.23 \\
\hline 14 & factor & 0.32 & 0.32 & 0.32 & 0.33 \\
\hline 16 & & 0.40 & 0.41 & 0.42 & 0.42 \\
\hline 18 & & 0.47 & 0.48 & 0.50 & 0.51 \\
\hline 12 & Annual energy & 51,300 & 51,500 & 50,100 & 50,100 \\
\hline 14 & production & 70,000 & 70,700 & 71,100 & 71,500 \\
\hline 16 & (kWh) & 87,600 & 89,200 & 91,700 & 92,700 \\
\hline 18 & & 103,300 & 105,500 & 110,500 & 111,900 \\
\hline 12 & Revenue & $\$ 3,590$ & $\$ 3,610$ & $\$ 3,510$ & $\$ 3,510$ \\
\hline 14 & (@7థ/kWh) & $\$ 4,900$ & $\$ 4,950$ & $\$ 4,980$ & $\$ 5,010$ \\
\hline 16 & & $\$ 6,130$ & $\$ 6,240$ & $\$ 6,420$ & $\$ 6,490$ \\
\hline 18 & & $\$ 7,230$ & $\$ 7,390$ & $\$ 7,740$ & $\$ 7,830$ \\
\hline 12 & Increase in & $0.0 \%$ & $0.3 \%$ & $-2.2 \%$ & $-2.2 \%$ \\
\hline 14 & production & $0.0 \%$ & $1.1 \%$ & $1.6 \%$ & $2.3 \%$ \\
\hline 16 & over baseline & $0.0 \%$ & $1.8 \%$ & $4.7 \%$ & $5.8 \%$ \\
\hline 18 & & $0.0 \%$ & $2.1 \%$ & $7.0 \%$ & $8.3 \%$ \\
\hline
\end{tabular}

NOTES: $\uparrow$ at $33 \mathrm{ft}$, assuming a $1 / 7$ th power law to hub height ( $80 \mathrm{ft}$ )

$\checkmark$ parameter values based on a Rayleigh wind speed distribution

TABLE 8. Effect of tested vortex generator configurations on annual performance of Carter Model 25 turbine 


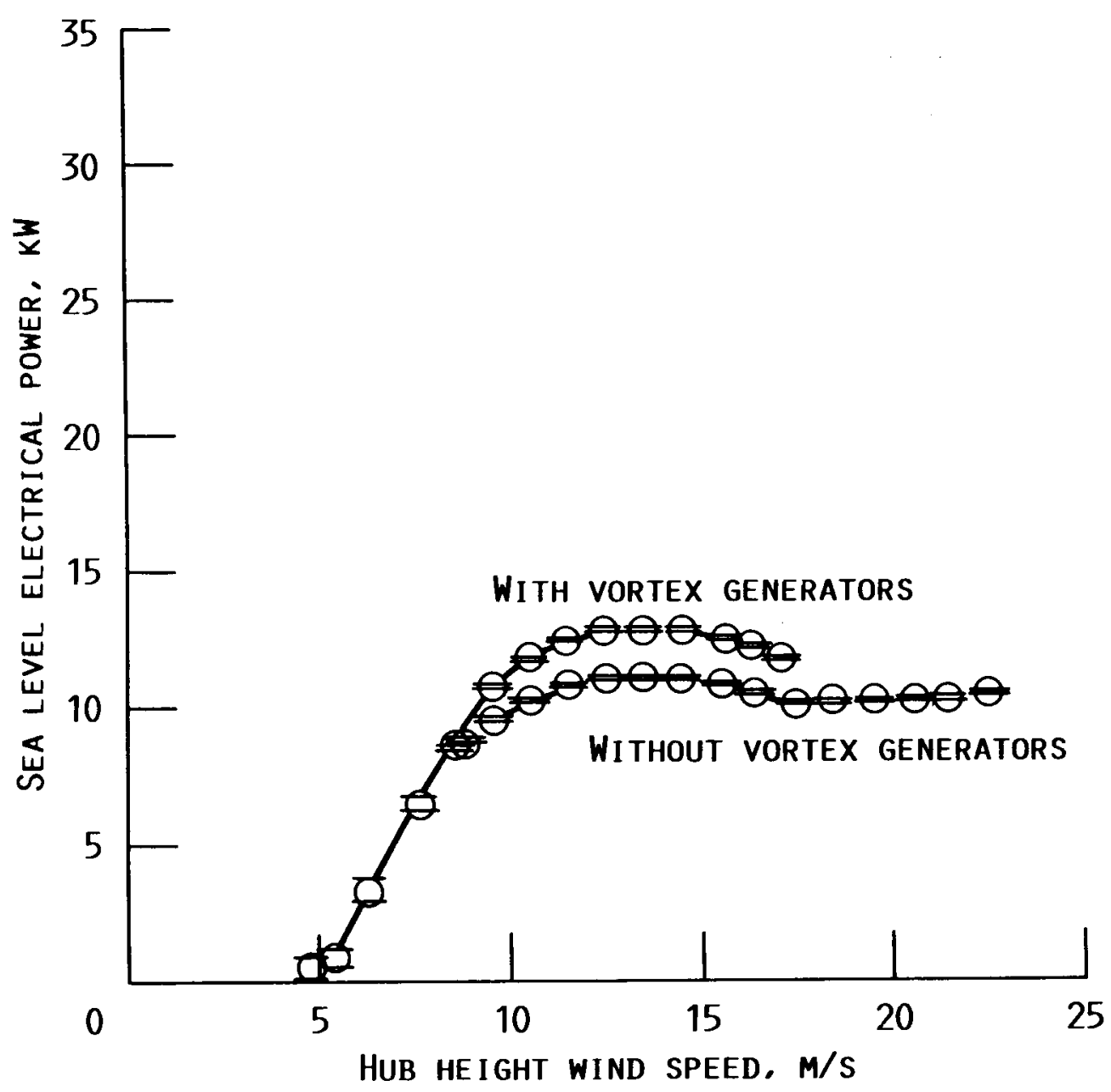

FIgURE 17. - EFFECT OF LEADING EDGE ROUGHNESS WITH AND WITHOUT VORTEX GENERATORS (CONFIGURATIONS 5 AND 6). 
alleviate some of the performance degradation due to the leading edge roughness, although their effect was not sufficient to bring the performance back up to the base line power curve. This may have been due to the large size of the roughness elements used in the tests. Actual dirt and bugs would not be as severe and the effect of the vortex generators could be expected to be correspondingly greater. In a real situation, a saturation level of roughness will exist because of the competing effects of rain and centrifugal force which both tend to keep the blades clean. It is noted that, because of the effect of the turbine repairs shown in figure 15 , the difference seen between the curves in figure 17 should actually be larger by about $2 \mathrm{~kW}$ at windspeeds below about $13 \mathrm{~m} / \mathrm{s}$ and smaller at wind speeds above $13 \mathrm{~m} / \mathrm{s}$. 


\section{CONCLUSIONS}

This study on the Carter Model 25 represents the completion of a series of preliminary investigations into the effect of vortex generators on a wide size range of horizontal axis wind turbines, similar programs having been completed by NASA on the large MOD-2 and mid-size MOD-0 machines. These tests have demonstrated that successful vortex generator arrangements for all sizes of wind turbines can be designed using simple geometric scaling laws. Results of the tests on the Carter machine showed that vortex generators increased power output significantly above 10 $\mathrm{m} / \mathrm{s}$ with only a small performance penalty at lower wind speeds, and that the vortex generators on the outboard parts of the blade were more effective than those on inner sections. The changes in the power curve represent a net increase in energy production for sites with annual wind speeds above about $13 \mathrm{mph}$ with a Rayleigh distribution. It was also observed that the vortex generators did, to some extent, alleviate the performance loss caused by leading edge roughness.

The conclusions of this study are summarized as follows:

1) Vortex generators can be used to significantly modify the power curve of all sizes of horizontal axis wind turbines.

2) For the Carter Model 25, the modification to the power curve was more sensitive to the addition of vortex generators to the outboard half span than to the inboard half of the blade.

3) All the configurations of vortex generators tested showed an increase in power output (up to about $5 \mathrm{~kW}$ in the best case) at wind speeds above $10 \mathrm{~m} / \mathrm{s}$ with only a small (less than $1 \mathrm{~kW}$ ) reduction in output at lower wind speeds.

4) For each configuration, the measured power curve represents a net increase in energy production for sites with annual wind speeds above about $13 \mathrm{mph}$ with a Rayleigh distribution.

5) In terms of energy production, the optimum configuration used vortex generators over the entire span, although this was only slightly better than vortex generators on the outboard half span only.

6) For the optimum case of full span coverage, the performance improvement amounts to almost $6 \%$ increase in energy production at a site with a mean wind speed of $16 \mathrm{mph}$, or a revenue increase of about $\$ 14,400$ per year per installed MW with an energy price of $7 \notin / \mathrm{kWh}$. At $18 \mathrm{mph}$, the average energy output is increased by $8 \%$.

7) Simple geometric scaling laws provide vortex generator designs which can make significant improvements to the performance of all sizes of horizontal axis wind turbines. Although the large number of design parameters precludes comprehensive testing for optimization, the magnitude of the measured effect on the power curve suggests that this 
method provides a design which is close to optimum.

8) The recommended vortex generator arrangement, tested at a chord Reynolds number between about $0.7 \times 10^{6}$ and $1.3 \times 10^{6}$, consists of a counterrotating arrangement of flat fins located at the $10 \%$ chord, with a $20^{\circ}$ angle of incidence, and with the following approximate dimensions:
a) length $=2.5 \%$ of local chord
b) height $=$ length $/ 4$
c) pair width $=10 \%$ of local chord
d) pair spacing $=15 \%$ of local chord between centerlines

9) Increasing the blade pitch angle has a similar effect on the power curve of a clean rotor as the addition of vortex generators.

10) Vortex generators can be used to reduce the sensitivity of rotor blades to an accumulation of bugs and dirt on their leading edge. 


\section{RECOMMENDATIONS}

It has been shown that a simple increase in blade pitch angle has an effect on the power curve similar to the addition of vortex generators. Also, despite experimental difficulties in maintaining a constant roughness, and the complications introduced by turbine repairs made part way through the field tests, it has been seen that vortex generators can alleviate the sensitivity of wind turbine blades to leading edge roughness caused by bugs and dirt. This latter effect is therefore viewed as their primary value in the wind turbine industry. Although in this study the vortex generators did not completely eliminate the effect of the leading edge roughness, the size of the roughness clements used was significantly larger than that typically encountered on an operating wind turbine. It is therefore possible that vortex generators can alleviate the effects of the bugs and dirt sufficiently to

eliminate or at least reduce the need for the periodic blade cleaning which is presently part of the routine maintenance at some windfarms.

It is noted that the effects of vortex generators depend very strongly on the airfoil design and on the roughness level. It is also noted that the relative equivalence of sandgrain roughness levels used in the experiment to actual natural roughness due to field fouling is not known.

In view of the above discussion, the following specific recommendations are made:

1) Measurements should be taken to determine the characteristic size of the actual natural roughness elements which accumulate on the leading edge of wind turbine blades, and of the time required, at different sites and in various conditions, for sufficient roughness to accumulate to significantly effect performance.

2) Further field tests should be carried out to study the use of vortex generators to reduce the sensitivity of certain wind turbines to the accumulation of dirt and bugs (fouling) on the leading edge of their blades. Performance measurements should be made on a number of different machines which experience this problem, beginning with clean blades and over a sufficient time period to allow a saturation level of 'natural' leading edge roughness to accumulate.

3) A study should be made of airfoil design features with a view to understanding what aspects of the flow field and pressure distribution are significant in airfoil fouling or to adverse separation response due to fouling, and to what extent adverse effects can be avoided by the shape of the airfoil profile alone.

4) A study should be carried out to investigate the use of vortex generators as an integral part of the design of airfoils for future wind turbines. 


\section{REFERENCES}

Abbott, I.H. and A.E. von Doenhoff (1959): Theory of wing sections. Dover Publications, Inc. New York. Page 143.

Bruynes, H. (1951): Fluid mixing device. U.S. Patent 2,558,816.

Corrigan, R.D. and J.M. Savino (1985): Vortex generators as a means for increasing rotor performance. Proceedings of the 20th Intersocicly Linergy Conversion Engineering Conference Vol. 3, Miami, Ilorida. SAE/P-85/164.

Gyatt, G.W. and P.B.S. Lissaman (1985): Development and testing of tip devices for horizontal axis wind turbines. NASA report CR-174991.

Jones, J.P. (1957): The calculation of the paths of vortices from a system of vortex generators and a comparison with experiment. Curr. Pap. Aero. Res.

Lissaman, P.B.S., R.E. Wilson, R.W. Thresher, and S.N. Walker (1979): A definitive generic study for the effect of high lift airfoils on wind turbine effectiveness. SERI/TR-98003-2.

McCullough, C.B., G.E. Nitzberg, and J.A. Kelly (1951): Preliminary investigation of the delay of turbulent flow separation by means of wedge-shaped bodies. Res. Memor. Nat. Adv. Comm. Aero, Wash. A50L12. (Available at TIL, Min. Supply, Lond. as NACA/TIL/2632.)

Miller, G.E. (1984): Comparative performance tests on the MOD-2 2.5MW wind turbine with and without vortex generators. Proc. Workshop on horizontal axis wind turbine technology (NASA CP to be published).

Savino, J.M., T.W. Nyland, A.G. Birchenough (Lewis Research Center) \& F.L. Jordan and N.K. Campbell (Langley Research Center) (1985): Reflection plane tests of a wind turbine blade tip section with ailerons. NASA TM-87018.

Schubauer, G.B. and W.G. Spangenberg (1959): Forced mixing in boundary layers. National Bureau of Standards, Washington, D.C.

Stephens, A.V. and G.A. Collins (1955): Turbulent boundary layer control by ramps or wedges. ACA Rep. Austr. Aero. Comm, Melbourne 55.

Sullivan, T.L. (1984): Effect of vortex generators on the power conversion performance and structural dynamic loads of the MOD-2 wind turbine. NASA TM-83680.

Tanner, L.H., H.H. Pearcey, and C.M. Tracy (1954): Vortex generators: their design and their effects on turbulent boundary layers. Rep. Aero. Res. Coun., London, 16487.

Taylor, H.D. (1947): The elimination of diffuser separation by vortex generators. Rep. United Aircraft. Corp. R-4012-3. 


\section{APPENDIX}

\section{Summarized specifications of the Carter Model 25 wind turbine}

\section{General:}

horizontal axis

downwind rotor

free yaw

$32 \mathrm{ft}$ diameter

2 bladed

$80 \mathrm{ft}$ hub height

$120 \mathrm{rpm}$ rotor

$25 \mathrm{~kW}$ rated power

cut-in wind spced around $4 \mathrm{~m} / \mathrm{s}$ (rpm controlled)

no cut out wind speed

3 phase induction generator, $1800 \mathrm{rpm}, 480$ volts

\section{Blades:}

taper and twist: inner $65 \%=$ non-linear, outer $35 \%=$ constant

airfoil: NACA23021@ root, NACA23012@tip

$4^{\circ}$ pre-cone

fiberglass and PVC foam construction

\section{Control system:}

stall controlled rotor (no cut-out wind speed), fixed pitch

large root cuff for starting torque

overspeed control by blade pitching under centrifugal load

disc brake operated manually or by excess vibration sensor 


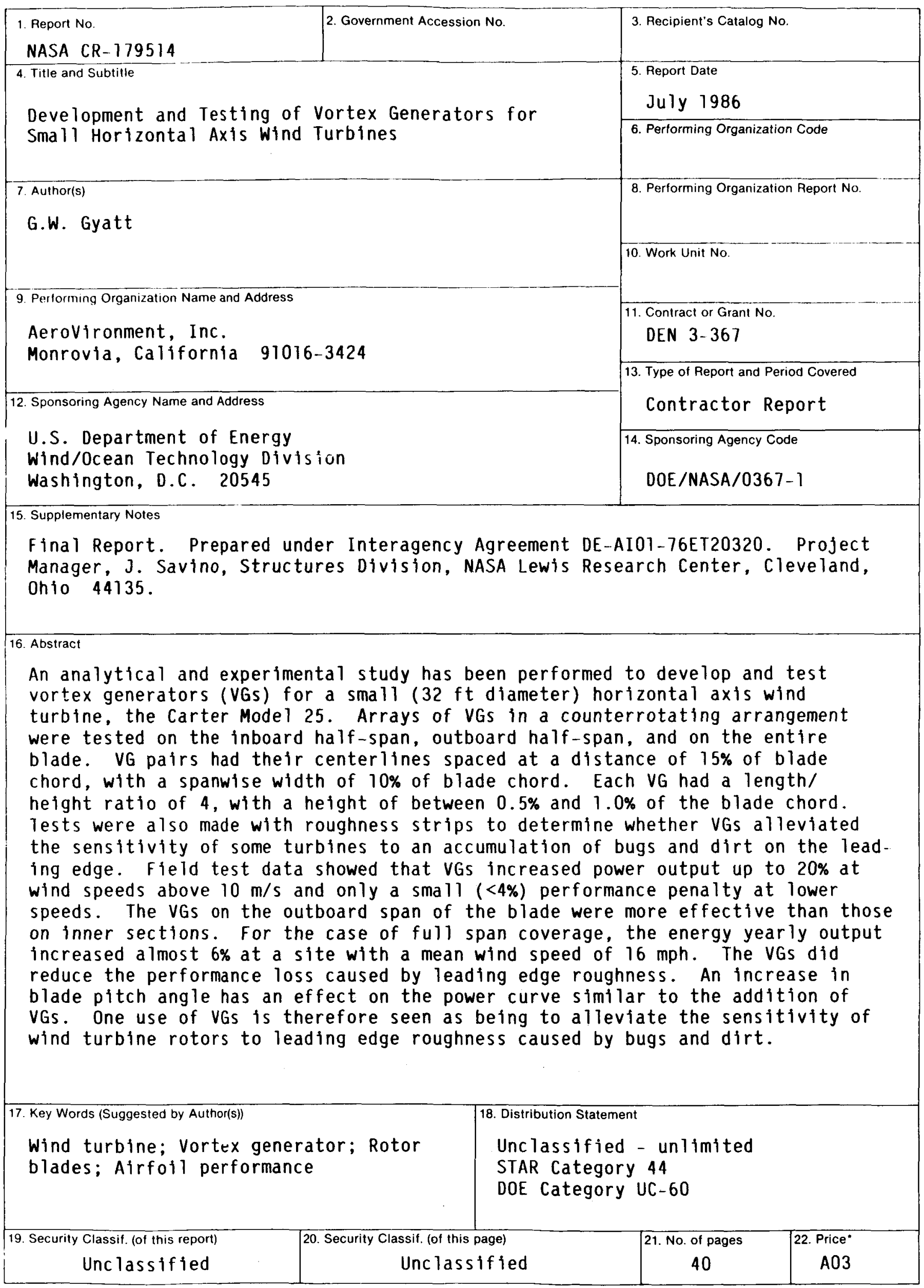

"For sale by the National Technical Information Service, Springfield, Virginia 22161 